\title{
Factors affecting the use of medicinal plants by migrants from rural areas of Brazilian Northeast after moving to a metropolitan region in Southeast of Brazil
}

\author{
Perla Carvalho Romanus ${ }^{1 *}$ (D) Fúlvio Rieli Mendes ${ }^{2}$ and Elisaldo de Araújo Carlini ${ }^{3}$
}

\begin{abstract}
Background: Ethnopharmacological studies about migrants reveal a dynamic process of knowledge and use of medicinal plants. In this study, we sought to elucidate quantitative and qualitatively the main factors influencing the use of medicinal plants by migrants from rural areas to an urban region in Brazil with traces of remnant natural vegetation.

Methods: Seven Northeastern individuals who migrated to the Southeastern Region of Brazil (Bororé Peninsula, in the city of São Paulo) were selected to participate in semi-structured interviews regarding the use of medicinal plants throughout their lives, and indicated an inhabitant in their hometown that would be able to accompany the field collections in each area. Socioeconomic, educational, family structure, and use of Western medicine data were provided during interviews with the individuals from their hometowns. Plant samples cited by the interviewees were collected both at the current place of residence and in their hometowns.

Results: The participants cited 131 plants and 315 recipes, being the main indications related to the gastrointestinal system, respiratory problems, and pain and inflammatory processes. We observed that most plant uses were maintained after migration. Higher percentages of maintenances and incorporations in plant uses occurred to exotic species, while replacements happen mainly to native plants. The introduction of new species into the migrants' therapeutics occurred mainly by observations of organoleptic similarities between the substituted plant and the incorporated species, conversations with neighbors, and contact with the television and print media. In addition, the public health system allowed the interviewees access to prophylactic drugs, leading to the discontinuation of certain recipes used in endemic diseases.

Conclusion: Migrants were exposed to information about new plants and their uses, new diseases, and socioeconomic and cultural differences that impacted their use of medicinal plants. Although migration to a more developed city facilitated access to public health and education, on the other hand, it made access to fresh medicinal plants difficult, causing some medicinal plants to be replaced or ceased to be used.
\end{abstract}

Keywords: Medicinal plants, Migration, Adaptation, Urban ethnomedicine, Bororé Peninsula, Cross-cultural adaptation

\footnotetext{
* Correspondence: perla.romanus@gmail.com

'Department of Psychobiology, UNIFESP, Rua Botucatu, 862, $1^{\circ}$ andar, prédio

Ciências Biomédicas, Vila Clementino, São Paulo, SP 04023-062, Brazil

Full list of author information is available at the end of the article
}

(c) The Author(s). 2018 Open Access This article is distributed under the terms of the Creative Commons Attribution 4.0 International License (http://creativecommons.org/licenses/by/4.0/), which permits unrestricted use, distribution, and reproduction in any medium, provided you give appropriate credit to the original author(s) and the source, provide a link to the Creative Commons license, and indicate if changes were made. The Creative Commons Public Domain Dedication waiver (http://creativecommons.org/publicdomain/zero/1.0/) applies to the data made available in this article, unless otherwise stated. 


\section{Background}

Ethnopharmacological research regarding migrants reveals a dynamic process of knowledge and use of medicinal plants. Despite adapting or incorporating new treatments for their illnesses, migrant subjects also preserve part of their past culture. Some of the factors that can influence this process are the reason for migration, social status, education, personal habits, lifestyle, and differences in the degree of development between the regions of origin and destination [1-4].

Numerous studies have evaluated the impact of the cultural syncretism on the adaptation of different groups of migrants, for example, people that migrated from Albania or Senegal to Italy $[5,6]$, from Haiti, Europe, and Africa to Cuba [7, 8], from South Asian or South American countries to UK [3, 9-11], from Macedonia to Albania [12], from Poland to Argentina [13, 14], and from Austria to Australia, Brazil, or Peru [15]. This adaptation is also observed in studies with nomad people [16] and migrants from geographically and culturally distinct regions of the same country, such as Brazilian subjects who migrated from the Northeastern Region to the Amazon region of the Acre and Purus rivers [17] and from the northeastern to southeast metropolitan region of São Paulo [18]. The migrants usually cherish and uphold values and traditions of their hometowns, such as festive dates, cuisine, music, local dialects, and the medicinal plants they already knew. At their new destination, they are introduced to novel uses for these plants, in addition to introducing their knowledge to local therapeutics as well [1, 19]. Additionally, they are exposed to a new environment where the acquisition of new species and the abandonment of certain plants of their therapeutic resource take place $[1,2]$.

Migration from rural to urban areas in metropolitan centers [18] or immigration from developing countries to big cities in developed countries have been previously studied [3, 4, 6, 9, 10, 20]. When migrants move to regions that have preserved vegetation or remain in contact with people from their hometown, the likelihood of maintaining the use of medicinal plants is higher, despite cultural and climatic adaptations [1, 21].

In this study, we sought to investigate, using quantitative and qualitative data, how the migration from rural areas of the Brazilian Northeast to the Bororé Peninsula (a community belonging to São Paulo metropolitan region, but with remaining forest areas) influenced the dynamics of the use of medicinal plants among the migrant subjects. In order to better understand the rationale behind the decision of whether or not to use medicinal plants after migration, ethnopharmacological and ethnographic data were collected both at the São Paulo site and on informants' cities of origin. Our hypothesis was that the migrants would maintain the use of the species that are also available in the host environment (new city) and discontinue the use or replace those not available in the metropolitan region.

\section{Methods \\ Locations (study areas)}

The Bororé Peninsula is located in the Billings Hydrographic Basin, which occupies a territory of $582.8 \mathrm{~km}^{2}$, located in the southeast portion of the metropolitan region of São Paulo, Southeast Brazil. Contrasting with the other regions of the city, it has low human occupation, with few buildings and access by ferry boat. It contains a large area of secondary Atlantic Forest in middle and advanced stages of regeneration [22].

During the survey period, the community of the Bororé Peninsula had approximately 2500 inhabitants (data obtained through the local Family Health Unit). Many inhabitants came from migratory flows in the 1960s and 1970s. There was one Basic Health Unit and one public school in the Bororé Peninsula, as well as electricity and telephone network, but there was no water supply, resulting in the need for residents to build artesian wells. Residents of the Bororé Peninsula could schedule weekly medical appointments at the Basic Health Unit, while elderly patients, pregnant women, and sick people with most serious health state received authorization to conduct tests and medications at home through government health employee.

The informants' hometowns are located in Bahia and Piaui (Northeast states of Brazil). Esplanada, Jitaúna, and Itabuna (in the state of Bahia) present the Atlantic Forest as a natural biome, while Novo Horizonte (Bahia), Piripiri, and Pavussú (in the state of Piauí) are located in regions where the prevalent biome is the Caatinga (dryland) (Fig. 1). The Caatinga is represented by a rainfall regime that, in the regional culture, encompasses two distinct seasons: summer (dry season) and winter (rainy season) (Fig. 2).

Basic sanitation, public health facilities, basic education (primary and secondary schools), public transport, and access to electricity in rural areas were precarious or absent in all visited cities. Although Itabuna city was an exception for most of the aforementioned issues, basic sanitation was absent in the visited rural area at the margin of the forest. Another concern was the presence of mining in new Horizonte, where miners could be seen working without any supervision or security. Extreme poverty was observed in some places, but according to the interviewees, it had been recently diminished as a consequence of the federal basic income transfer policy called "Bolsa Família" which pays a small salary for poor families.

\section{Selection of participants, interviews, and sample collection}

Approximately 300 houses were visited in the Bororé Peninsula between July 2005 and August 2006. During 


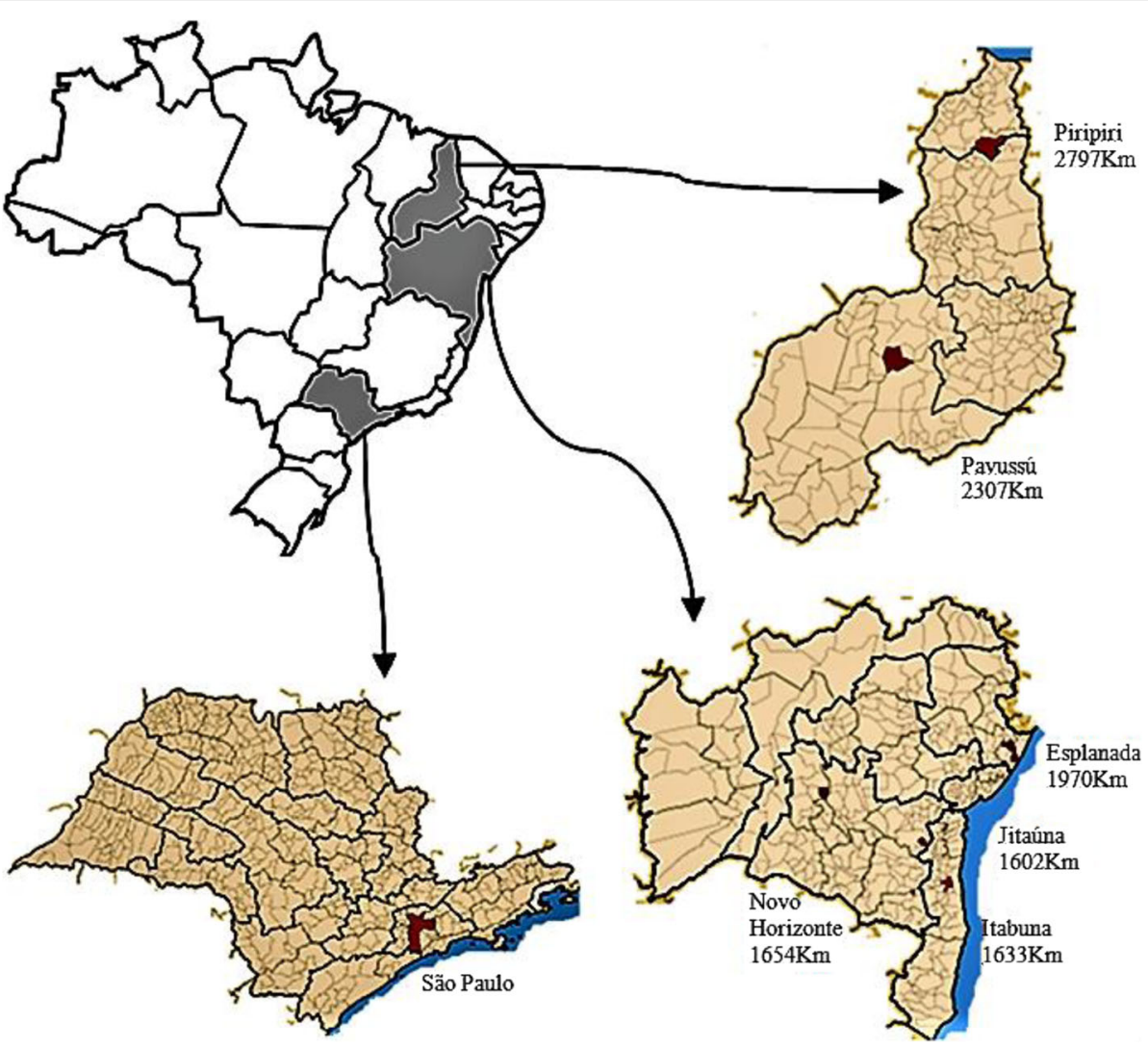

Fig. 1 Location of the cities of origin of the interviewees, indicating their distances to São Paulo city

this time, we collected general information about the local community and set some key-informants (community leaders) to assist in selecting the study participants. For this study, we selected people who migrated from the Northeast Region of Brazil and met the following criteria: (a) were considered specialists in medicinal plants by their neighbors in the Bororé community; (b) used native plants regularly in their hometown; and (c) were able to indicate at least one close person (friend or relative) who could assist in ethnographic research and plant collection in their hometown. Seven people with these characteristics were selected (data summarized in Table 1).

Survey methods were based on anthropological and botanical concepts [23] to obtain qualitative and quantitative data about the use of medicinal plants. Approximately 40 informal and semi-structured visits and interviews were carried out with the migrants (informants) to obtain their personal data such as age, marital status, main occupation, educational level, religion, family structure, city of birth,

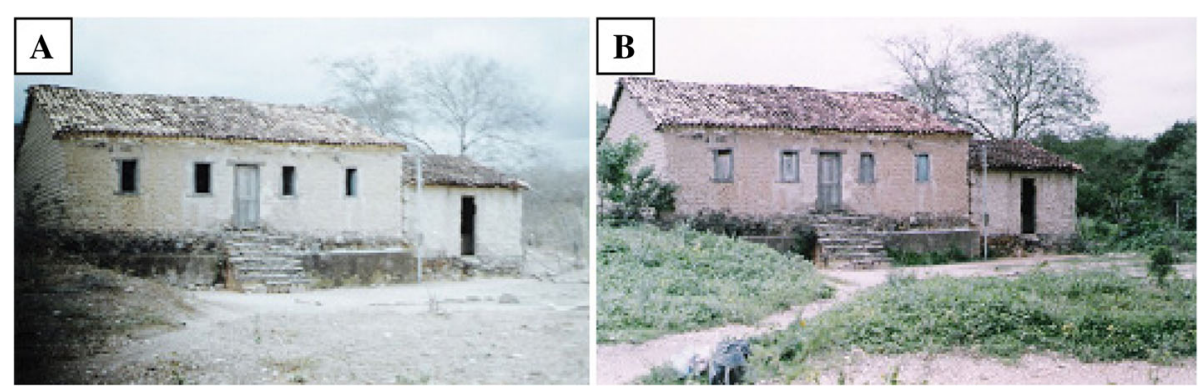

Fig. 2 Residence in a rural area of the city of Novo Horizonte, state of Bahia. a Summer equals dry season. b Winter equals rainy season 
Table 1 Personal data of the interviewees

\begin{tabular}{|c|c|c|c|c|c|c|c|c|c|}
\hline Interviewee $^{1}$ & $\begin{array}{l}\text { Age } \\
\text { (year) }\end{array}$ & Gender & Origin & $\begin{array}{l}\text { Hometown } \\
\text { biome }\end{array}$ & $\begin{array}{l}\text { Trigger for } \\
\text { migration }\end{array}$ & $\begin{array}{l}\text { Time after } \\
\text { migration (years) }\end{array}$ & $\begin{array}{l}\text { Scholar } \\
\text { degree }\end{array}$ & Profession & $\begin{array}{l}\text { Grows medicinal } \\
\text { plants at the yard? }\end{array}$ \\
\hline BA1 & 68 & Male & Itabuna, BA & Atlantic Forest & Family & 15 & $\begin{array}{l}\text { Informal } \\
\text { literacy }\end{array}$ & Housekeeper & Yes \\
\hline BA2 & 53 & Female & $\begin{array}{l}\text { Novo } \\
\text { Horizonte, BA }\end{array}$ & Caatinga & Curiosity & 15 & Illiterate & Housewife & Yes \\
\hline BA3 & 62 & Male & Jitaúna, BA & Atlantic Forest & $\begin{array}{l}\text { Financial } \\
\text { improvement }\end{array}$ & 20 & $\begin{array}{l}\text { Elementary } \\
\text { school }\end{array}$ & Housekeeper & No \\
\hline BA4 & 49 & Female & Jitaúna, BA & Atlantic Forest & $\begin{array}{l}\text { Financial } \\
\text { improvement }\end{array}$ & 20 & $\begin{array}{l}\text { Elementary } \\
\text { school }\end{array}$ & Unemployed & No \\
\hline BA5 & 55 & Female & Esplanada, BA & Atlantic Forest & Curiosity & 15 & $\begin{array}{l}\text { Elementary } \\
\text { school }\end{array}$ & Housekeeper & Yes \\
\hline PI1 & 48 & Female & Piripiri, PI & Caatinga & $\begin{array}{l}\text { Financial } \\
\text { improvement }\end{array}$ & 20 & $\begin{array}{l}\text { Elementary } \\
\text { school }\end{array}$ & House maid & Yes \\
\hline $\mathrm{Pl} 2$ & 63 & Male & Pavussu, PI & Caatinga & $\begin{array}{l}\text { Financial } \\
\text { improvement }\end{array}$ & 20 & $\begin{array}{l}\text { Informal } \\
\text { literacy }\end{array}$ & Gardener & Yes \\
\hline
\end{tabular}

${ }^{1} B A$ migrants from the state of Bahia, $P I$ migrants from the state of Piauí

migratory journey, motive that led to migration, and housing time. Using field notebooks, guidebooks, and by participant observation method (direct observation) $[23,24]$, we also obtained data about usual diet, use of the conventional health system, and allopathic medicines, as well as detailed information on each medicinal plant known to the interviewee. We then collected the botanical material, whenever possible, and we registered the plant popular names, physical characteristics, indications (popular uses), used parts, methods of preparation, routes of administration, doses, frequency, contraindications, adverse effects, and any other relevant characteristics. Each indication (containing the part used and method of preparation) was considered one recipe. Some recipes contained two or more species (formulas). The same taxon and recipe would be cited by more than one informant. Plants cited by the informants, but not available in the Bororé Peninsula, were not collected in this phase of the study, but all relevant information was recorded to allow the subsequent localization of the species at the migrant's cities of origin.

In the second phase of the study (between September and November 2006), the fieldwork was performed at the interviewees' hometowns, where nine friends or relatives assisted as local guides for botanical collections. Local guides were informed of the popular name, medicinal use, and main morphological and organoleptic characteristics of the plants cited during the interviews in the peninsula of Bororé in order to increase the chances of finding the correct species. Books on Brazilian medicinal flora (see Additional file 1) were consulted in order to obtain data on their geographical distribution and their popular names to correlate with the names cited by the interviewees. This information was useful to facilitate finding the plants in the city of origin of each participant. The plants found and collected during the second phase of the study were subsequently showed to the migrants to confirm that they matched with the cited species.

The material collected in Bororé Peninsula and in the informants' hometown was identified at the Botany Institute of the State of São Paulo, and the vouchers specimens were deposited at the herbarium of the Federal University of ABC. The website "Flora do Brazil" [25] and several books were consulted to determine if the species were native, naturalized, or exotic (Additional file 1). Plants purchased in supermarkets by the participants were not identified by collection; instead, the botanical species or possible genus was suggested according to the organoleptic properties cited by the respondents, or by the information contained in their commercial packages (when available), as in the case of tea bags.

Considering the context of human migration, the adaptation in the use of medicinal plants was categorized as follows [18, 26]: (1) maintenance-when a plant known in the city of origin has its indication kept in the current location of residence; (2) replacement-there was an exchange of a medicinal plant used in the hometown for another species used for the same purpose; (3) incorporation-new indication for an already known plant or use of a new species for a specific purpose; (4) discontinuationthe species ceased to be used because the disease is uncommon in the current place of residence or the migrant preferred the use of allopathic medicine or an industrialized product in place of the plant.

\section{Quantitative analysis}

The data collected was entered in a worksheet containing the plant vernacular name, popular uses, parts employed, method of preparation, route of administration, and whether the plant use was maintained after migration, replaced, discontinued, or if a new plant or indication 
(recipe) was incorporated at the host place. Each recipe was included as a single line in the table; when two or more participants cited an identical recipe, it was grouped as a single entry, but the total number of citations was counted in the quantitative analysis. After botanical identification, the scientific name, family, and the origin of the species (native/naturalized or exotic) were included in the worksheet. We then classified the popular uses (complaints, ethnomedical indications, and other applications) cited by the informants into 15 categories (adapted from the International Classification of Diseases-ICD-11) [27]. The data generated was used to calculate the informant's consensus factor (ICF) and index of relative importance (RI), as detailed below.

The level of homogeneity among information provided by the seven participants was calculated using the formula ICF $=N_{\text {ur }}-N_{\mathrm{t}} /\left(N_{\text {ur }}-1\right)$, where $N_{\text {ur }}$ is the number of use reports from informants for a particular plant use category and $N_{\mathrm{t}}$ is the number of species that are used for that category for all participants [28, 29].

The RI of the main species cited by the informants was calculated by the formula $\mathrm{RI}=\mathrm{Ni} / \mathrm{Nc}$ where $\mathrm{Ni}$ is the number of informants that cited this species and Nc is the total number of citations of the species.

All taxa and recipes were used in the calculation of ICF and RI, independent of being maintained, replaced, incorporated, or discontinued.

\section{Qualitative analysis}

To better understand the main factors that contributed to the dynamics of medicinal plant use among the migrant participants of this study, the first author (Romanus, PC) recorded notes during the interviews in her field notebook and did general observations for further analysis. We subsequently used these notes to qualitatively discuss some strategies adopted by the seven interviewees concerning the use of medicinal plants after their migration. We sought to understand and discuss the most relevant aspects that influenced the dynamics of medicinal plant use, according to the participants' reports and interviewer perception.

\section{Results and discussion}

\section{Migrants selection}

Only seven people that fulfilled the selection criteria consented to participate in the study, being 4 women and 3 men with average age of 56.9 years old (Table 1). These informants migrated from Bahia and Piauí states (Northeast of Brazil) around 15-20 years before the study, and the biome in their place of origin was Atlantic Forest (interviewees BA1, BA3, BA4, and BA5) and Caatinga (BA2, PI1, and PI2). All the informants stated that they used medicinal plants in their hometowns and still use in the host place, but two (BA3 and BA4) were not able to grow medicinal plants in their yards at the Bororé Peninsula. The informants had only informal literacy or elementary school and, at the time of the interviews, worked as a housekeeper, housemaid, or gardener in their neighborhood. They also informed the main reasons for migration: financial improvement (4 participants), "curiosity about the life in a big city" (2 participants), or to live close to the family (1 participant).

Similarly to what was reported by Garcia et al. [18], the migrants stated that they learned about medicinal plants with relatives in their hometown and acquired new knowledge from books, media, and neighbors after their migration.

\section{Sample collection and data analysis}

The 131 plants cited during the field work at Bororé Peninsula and in the cities of Bahia and Piauí states are shown in Tables 2, 3, 4, and 5. Most taxa were identified, belonging to 51 families, where the most common were Lamiaceae (14 species), Asteraceae and Fabaceae (13 species), and Euphorbiaceae (11 species). The informants cited 315 recipes as part of several indications (popular uses). The plant parts most employed in the recipes were leaves and aerial parts, followed by barks, branches, and seeds, while the most common methods of preparation were as infusion, syrup, maceration, and decoction, respectively. This data corroborates previous reports in the literature, with these botanical parts and methods of preparation being the most cited. According to Gazzaneo et al. [29], communities living near humid forests tend to use plant leaves, while barks and roots are preferred by people living in dry regions because most plants shed their leaves in dry season. In our study, we observed a substantial use of bark and root of Caatinga species.

The informants also mentioned 15 recipes containing two or more plants and informed when these recipes were changed after migration (Table 6). These recipes were not unchangeable, since they stated that some plants could be included or replaced keeping the formula similarly effective.

\section{Therapeutic categories and informant's consensus factor}

The popular uses cited by the participants were grouped in 15 therapeutic classes (Table 7). The most relevant categories of use in our sample were respiratory $(62$ citations), gastrointestinal (58 recipes) and inflammation, pain and fever (55 citations). A similar study with people who migrated from Northeastern Brazil to Diadema (also a metropolitan region of São Paulo) found the same categories as the most cited [18]. In fact, studies with urban population have shown that the use of medicinal plants is more 


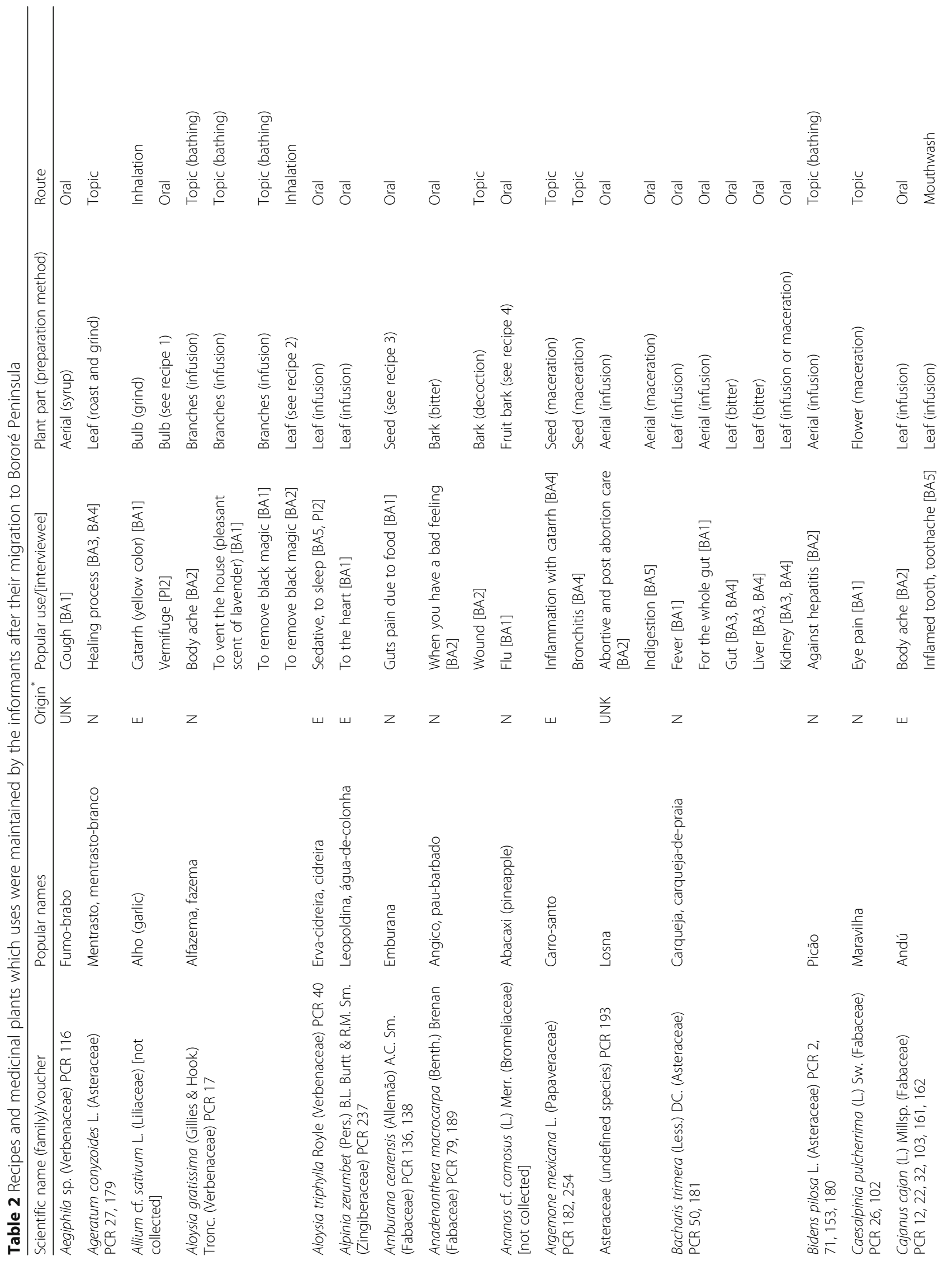




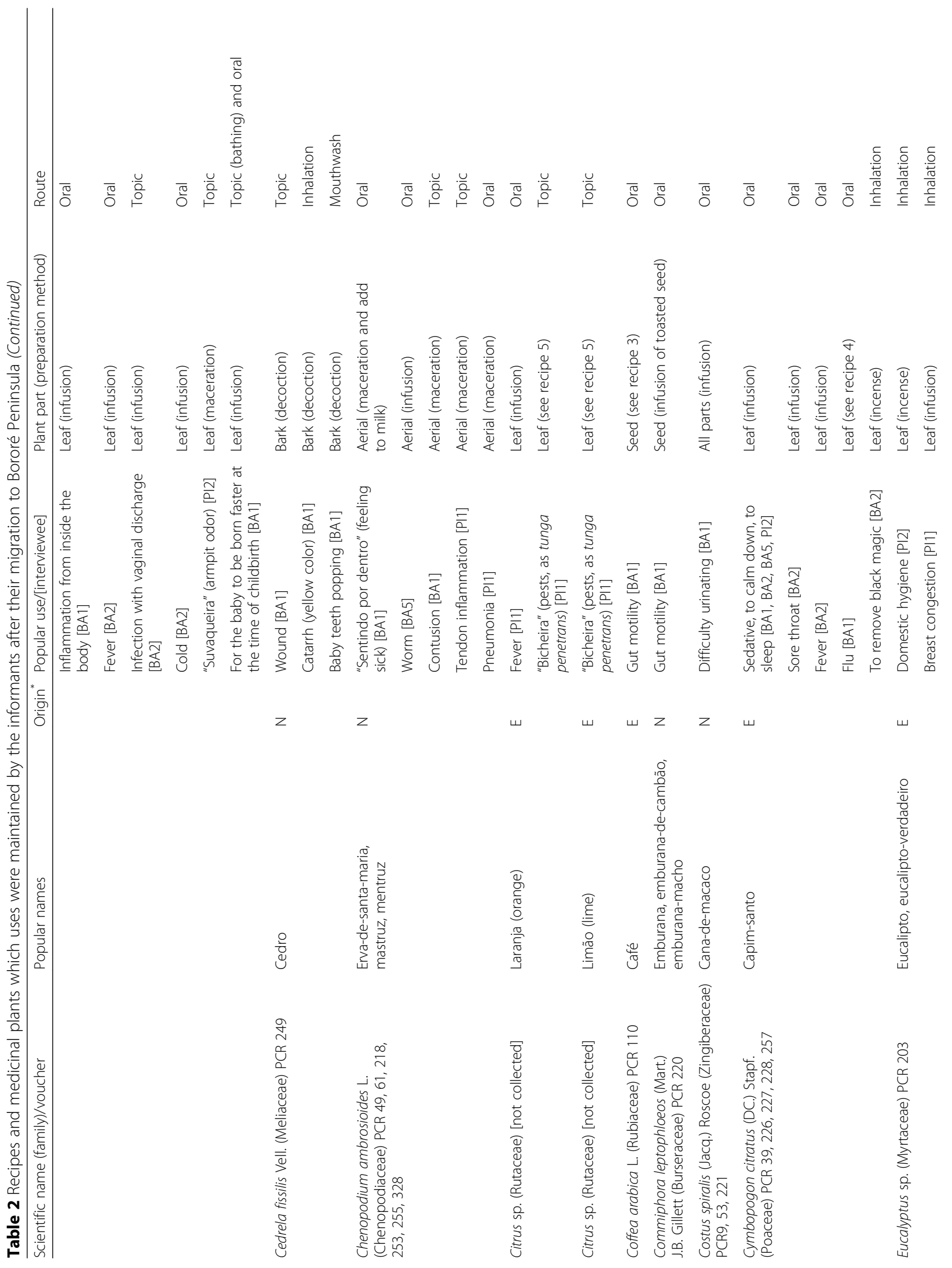




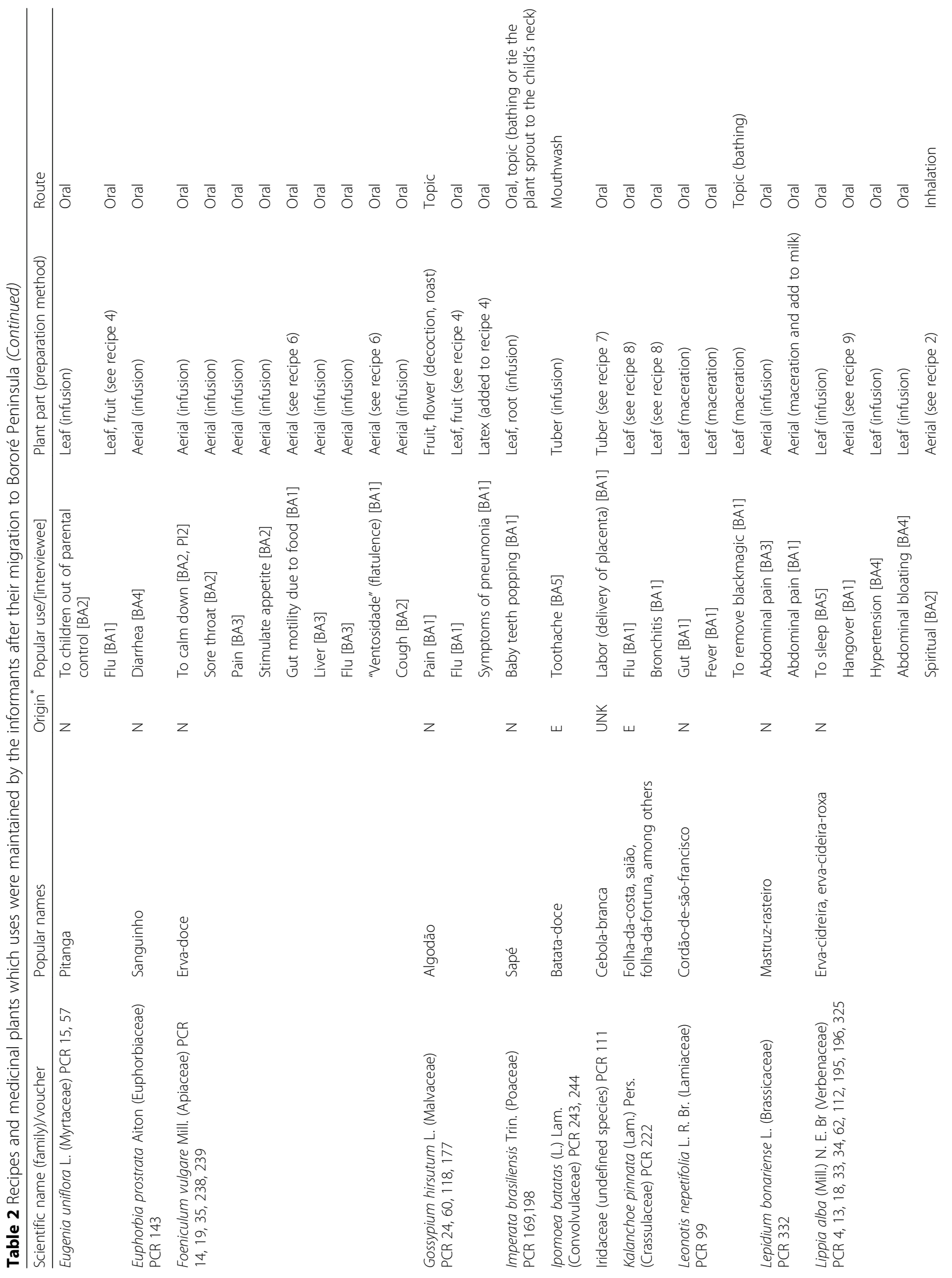




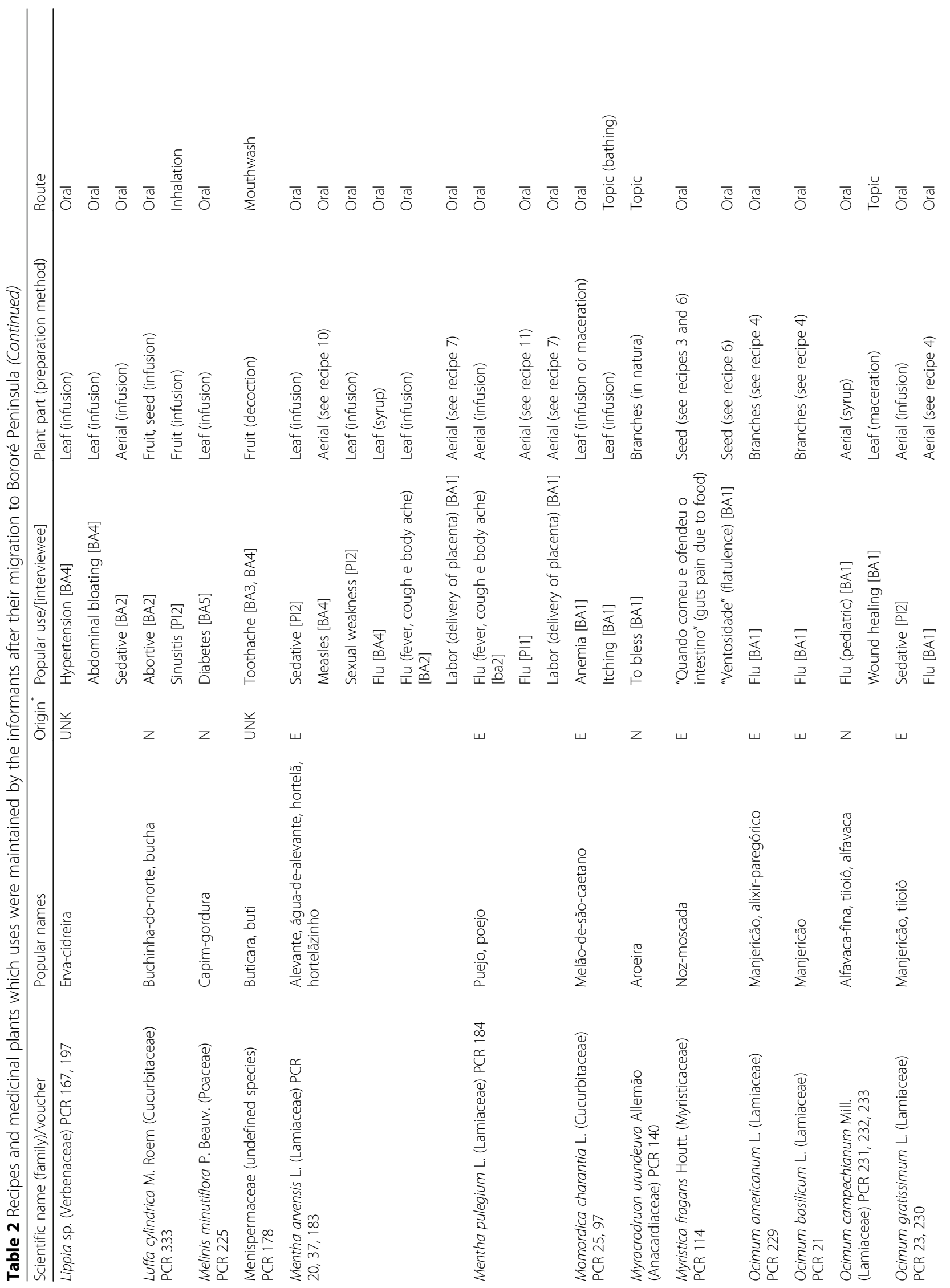




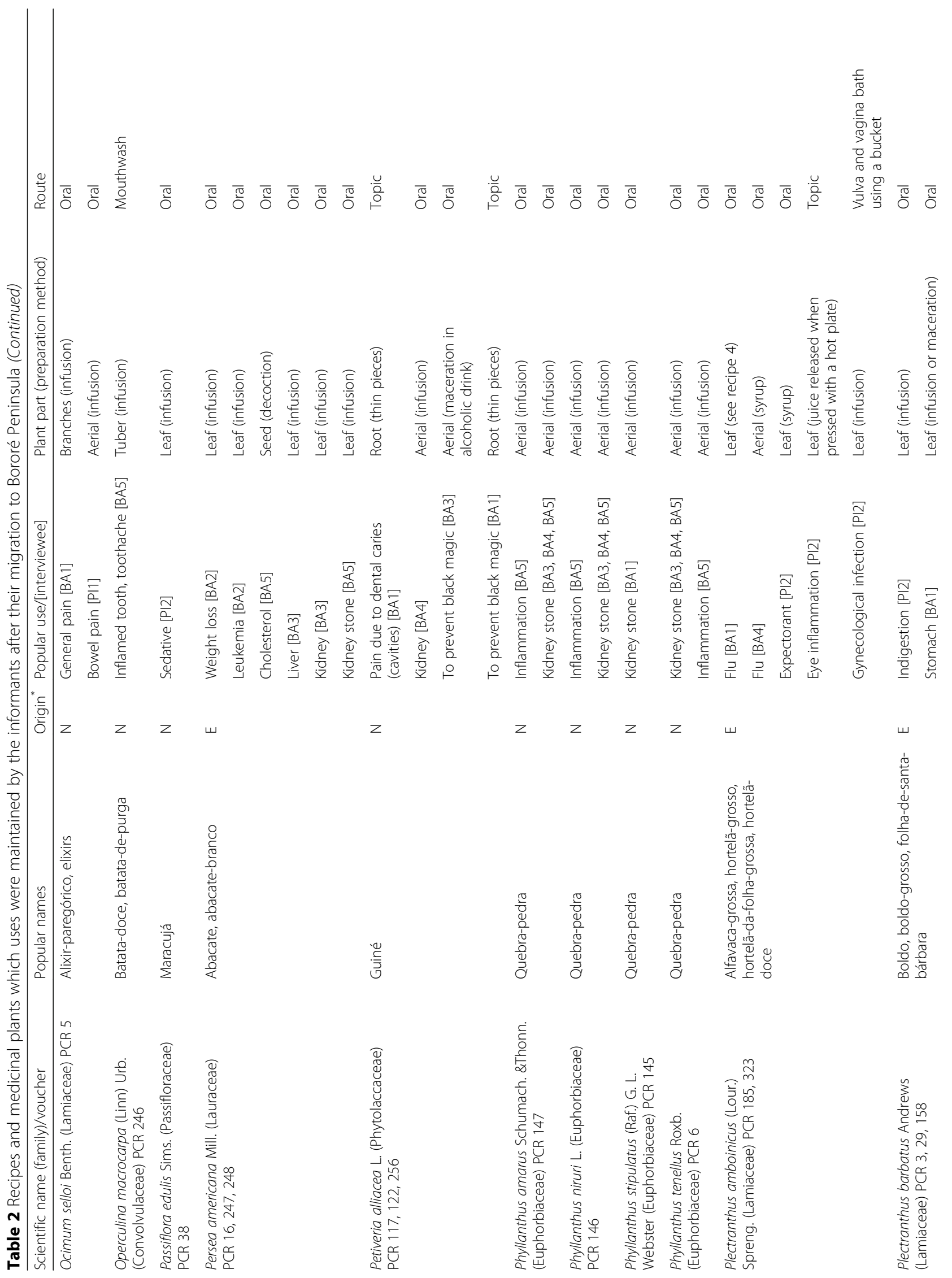




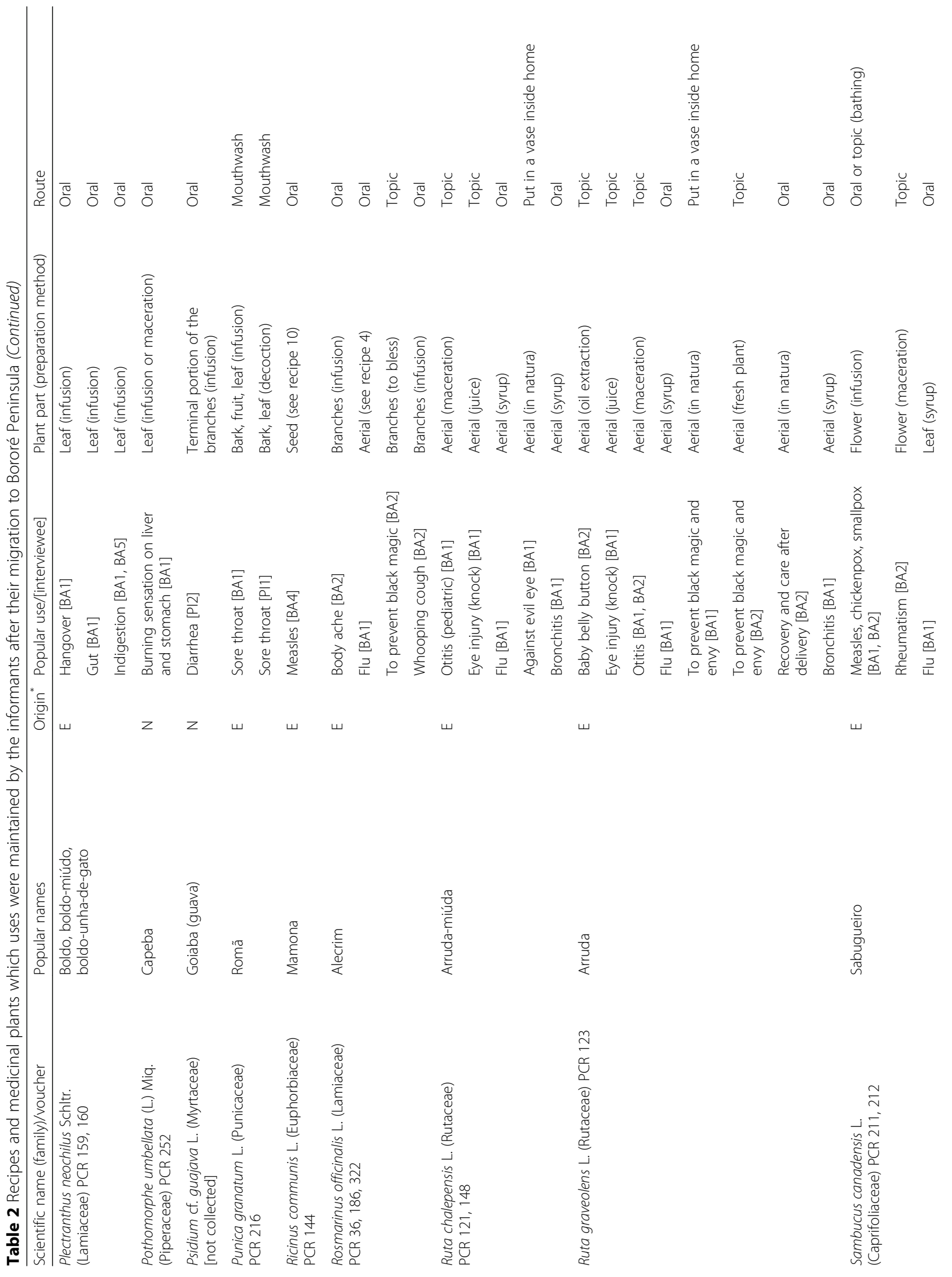




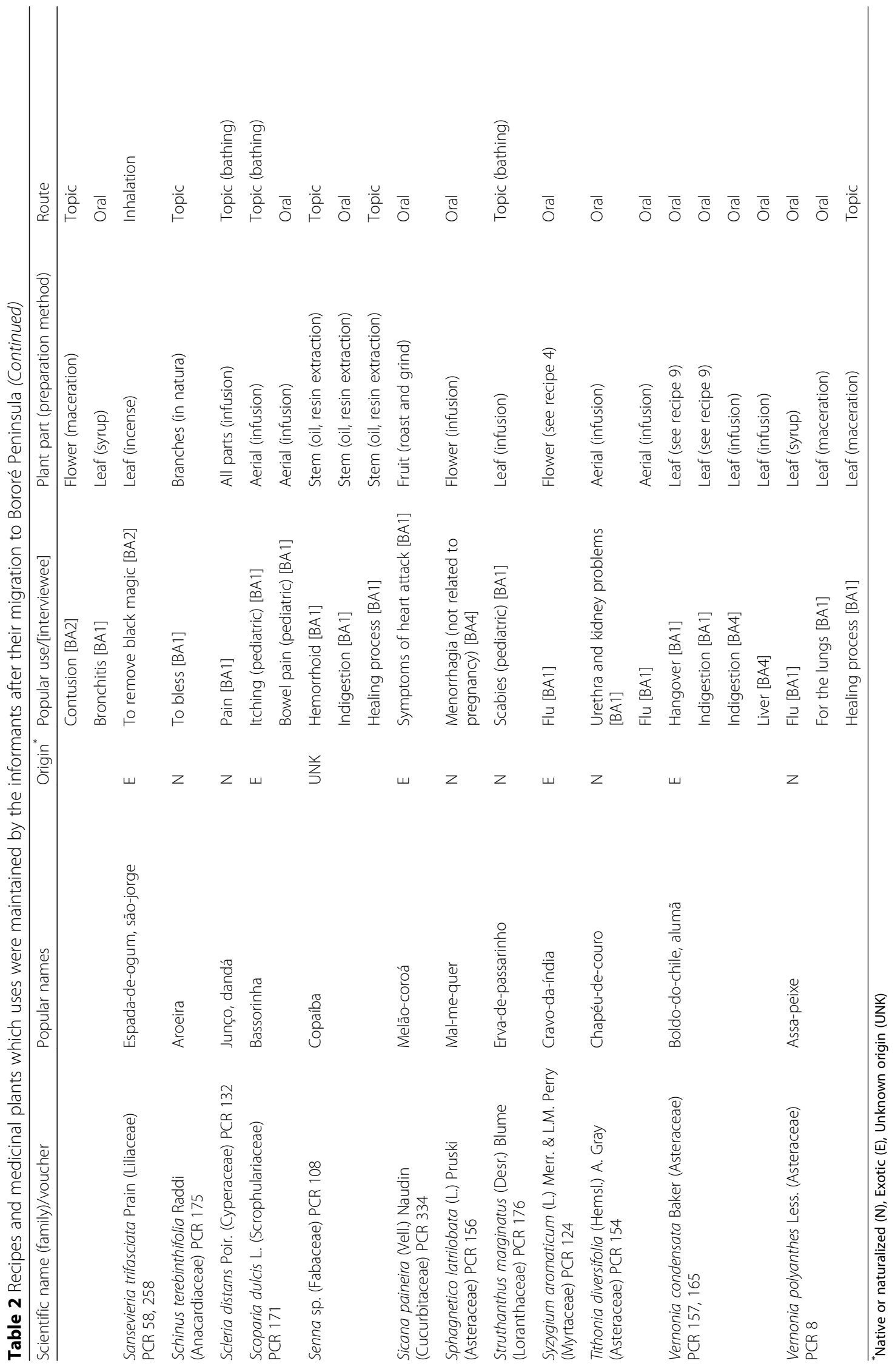


Table 3 Recipes and medicinal plants from the origin place which uses were replaced by the informants after their migration to Bororé Peninsula. The plants were replaced by other species already known and with similar uses (see Table 2-maintenance) or by new species (Table Table 5 - incorporation)

\begin{tabular}{|c|c|c|c|c|c|}
\hline Scientific name (family)/voucher & Popular names & Origin $^{*}$ & $\begin{array}{l}\text { Popular use/ } \\
\text { [interviewee] }\end{array}$ & $\begin{array}{l}\text { Plant part (preparation } \\
\text { method) }\end{array}$ & Route \\
\hline $\begin{array}{l}\text { Acacia adhaerens Benth. (Fabaceae) } \\
\text { PCR } 82\end{array}$ & Unha-de-gato & $\mathrm{N}$ & To bless [BA2] & Branches (in natura) & Topic \\
\hline $\begin{array}{l}\text { Acosmium dasycarpum (Vogel) } \\
\text { Yakovlev (Fabaceae) PCR } 131\end{array}$ & Raiz-d'anta & $\mathrm{N}$ & Stomachache [BA2] & Bark (decoction) & Oral \\
\hline $\begin{array}{l}\text { Ageratum conyzoides L. (Asteraceae) } \\
\text { PCR 27, } 179\end{array}$ & $\begin{array}{l}\text { Mentrasto, } \\
\text { mentrasto-branco }\end{array}$ & N & Dungal infection [BA5] & Aerial (topic, bathing) & $\begin{array}{l}\text { Topic } \\
\text { (bathing) }\end{array}$ \\
\hline \multirow{2}{*}{$\begin{array}{l}\text { Amburana cearensis (Allemão) A.C. Sm. } \\
\text { (Fabaceae) PCR 136, } 138\end{array}$} & \multirow[t]{2}{*}{ Emburana } & \multirow[t]{2}{*}{ N } & Headache [BA2] & Seed (see recipe 3 ) & Oral \\
\hline & & & Indigestion [BA2] & $\begin{array}{l}\text { Seed (toasting and brewing } \\
\text { together with coffee) }\end{array}$ & Oral \\
\hline $\begin{array}{l}\text { Anacardium cf. occidentale L. } \\
\text { (Anacardiaceae) [not collected] }\end{array}$ & Cajú (cashew) & $\mathrm{N}$ & Gut motility [BA2] & Fruit (in natura) & Oral \\
\hline \multirow[t]{3}{*}{$\begin{array}{l}\text { Anadenanthera macrocarpa (Benth.) } \\
\text { Brenan (Fabaceae) PCR 79, } 189\end{array}$} & \multirow[t]{3}{*}{ Angico, pau-barbado } & \multirow[t]{3}{*}{$\mathrm{N}$} & $\begin{array}{l}\text { Blood purifying } \\
{[\mathrm{PI} 1, \mathrm{PI}]}\end{array}$ & Bark (decoction) & Oral \\
\hline & & & Flu [PI1] & Bark (see recipe 12) & Oral \\
\hline & & & Flu [PI2] & Bark (syrup) & Oral \\
\hline \multirow[t]{2}{*}{ Arecaceae (undefined species) PCR 193} & \multirow[t]{2}{*}{ Quitara } & \multirow[t]{2}{*}{ UNK } & Flu [BA1] & Root (see recipe 8) & Oral \\
\hline & & & Bronchitis [BA1] & Root (see recipe 8) & Oral \\
\hline Cestrum sp. (Solanaceae) PCR 107, 170 & Cuarana & UNK & $\begin{array}{l}\text { To remove black } \\
\text { magic }[\mathrm{BA} 1]\end{array}$ & Tuber (incense) & Inhalation \\
\hline \multirow[t]{2}{*}{ Combretum sp. (Combretaceae) PCR 92} & \multirow[t]{2}{*}{ Mufumbá } & \multirow[t]{2}{*}{ UNK } & Inflammation [PI2] & $\begin{array}{l}\text { Bark (soak in water, } \\
\text { powder) }\end{array}$ & Topic \\
\hline & & & $\begin{array}{l}\text { Stop bleeding (injuries } \\
\text { and scratches) [PI2] }\end{array}$ & $\begin{array}{l}\text { Bark (soak in water, } \\
\text { powder) }\end{array}$ & Topic \\
\hline \multirow[t]{2}{*}{$\begin{array}{l}\text { Commiphora leptophloeos (Mart.) } \\
\text { J.B. Gillett (Burseraceae) PCR } 220\end{array}$} & \multirow[t]{2}{*}{$\begin{array}{l}\text { Emburana, emburana-de- } \\
\text { cambão, emburana-macho }\end{array}$} & \multirow[t]{2}{*}{ N } & Headache [BA2] & $\begin{array}{l}\text { Seed (toast, grind and mix } \\
\text { with oil) }\end{array}$ & Oral \\
\hline & & & Indigestion [BA2] & Seed (toast, soak in water) & Oral \\
\hline $\begin{array}{l}\text { Croton echioides Müll. Arg. (Euphorbiaceae) } \\
\text { PCR } 268\end{array}$ & Velame & N & Emetic [PI2] & $\begin{array}{l}\text { Root (maceration, soak in } \\
\text { water) }\end{array}$ & Oral \\
\hline $\begin{array}{l}\text { Croton betulaster Müll. Arg. (Euphorbiaceae) } \\
\text { PCR } 267\end{array}$ & Pimentinha & $\mathrm{N}$ & $\begin{array}{l}\text { To calm children } \\
\text { down }[\mathrm{BA} 2]\end{array}$ & Root (infusion) & Oral \\
\hline $\begin{array}{l}\text { Cymbopogon densiflorus (Steud.) Stapf. } \\
\text { (Poaceae) PCR } 115\end{array}$ & Capim-de-aruanda & N & $\begin{array}{l}\text { To remove black } \\
\text { magic }[\mathrm{BA} 1]\end{array}$ & Aerial (incense) & Inhalation \\
\hline $\begin{array}{l}\text { Diptychandra aurantiaca Tul (Fabaceae) } \\
\text { PCR } 204\end{array}$ & Birro-branco & $\mathrm{N}$ & Emetic [P|2] & Bark (decoction) & Oral \\
\hline Fabaceae (undefined species) PCR 129 & $\begin{array}{l}\text { Birro-cangalheiro, } \\
\text { birro-branco }\end{array}$ & UNK & Emetic [P|2] & Root (maceration) & Oral \\
\hline Fevillea trilobata L. (Cucurbitaceae) PCR 151 & Gendiroba & $\mathrm{N}$ & Gut motility [BA1] & $\begin{array}{l}\text { Seed, except pericarp } \\
\text { (toast and add to coffee) }\end{array}$ & Oral \\
\hline \multirow[t]{2}{*}{$\begin{array}{l}\text { Gallesia integrifolia (Spreng.) Harms } \\
\text { (Phytolaccaceae) PCR } 217\end{array}$} & \multirow[t]{2}{*}{ Pau-d'alho } & \multirow[t]{2}{*}{ N } & Pain [BA1] & Stem (decoction) & $\begin{array}{l}\text { Topic } \\
\text { (bathing) }\end{array}$ \\
\hline & & & $\begin{array}{l}\text { To remove black } \\
\text { magic }[\mathrm{BA} 1]\end{array}$ & Stem (decoction) & $\begin{array}{l}\text { Topic } \\
\text { (bathing) }\end{array}$ \\
\hline $\begin{array}{l}\text { Hymenaea courbaril L. var. stilbocarpa (Hayne) } \\
\text { Lee \& Langenhein (Fabaceae) PCR 74, } 130\end{array}$ & Jatobá, jatobá-mirim & $\mathrm{N}$ & Flu [PI1] & Bark (see recipe 12) & Oral \\
\hline $\begin{array}{l}\text { Hymenaea stigonocarpa Mart. ex Hayne var. } \\
\text { pubescens Benth. (Fabaceae) PCR 73, } 78\end{array}$ & Jatobá, jatobá-do-campo & $\mathrm{N}$ & Flu [PI1] & Bark (see recipe 12) & Oral \\
\hline $\begin{array}{l}\text { Jacaranda puberula Cham. (Bignoniaceae) } \\
\text { PCR } 67\end{array}$ & $\begin{array}{l}\text { Garobinha-do-mato, } \\
\text { carobinha }\end{array}$ & $\mathrm{N}$ & Allergy [P|1] & Branches (infusion) & $\begin{array}{l}\text { Topic } \\
\text { (bathing) }\end{array}$ \\
\hline Jacaranda sp. (Bignoniaceae) PCR 209, 210 & Jacarandá & UNK & To bless [BA1] & Aerial (incense) & Topic \\
\hline
\end{tabular}


Table 3 Recipes and medicinal plants from the origin place which uses were replaced by the informants after their migration to Bororé Peninsula. The plants were replaced by other species already known and with similar uses (see Table 2-maintenance) or by new species (Table Table 5 - incorporation) (Continued)

\begin{tabular}{|c|c|c|c|c|c|}
\hline Scientific name (family)/voucher & Popular names & Origin $^{*}$ & $\begin{array}{l}\text { Popular use/ } \\
\text { [interviewee] }\end{array}$ & $\begin{array}{l}\text { Plant part (preparation } \\
\text { method) }\end{array}$ & Route \\
\hline Jatropha curcas L. (Euphorbiaceae) PCR 259 & $\begin{array}{l}\text { Pinhão-branco, } \\
\text { pinhão-manso }\end{array}$ & $\mathrm{N}$ & Skin burn [BA2] & Latex (ointment) & Topic \\
\hline $\begin{array}{l}\text { Jatropha gossypiifolia L. (Euphorbiaceae) } \\
\text { PCR } 261,262\end{array}$ & Pinhão-roxo & E & $\begin{array}{l}\text { Home protection } \\
\text { [BA2] }\end{array}$ & Aerial (in natura) & - \\
\hline $\begin{array}{l}\text { Julocroton fuscescens (Spreng.) Baill. } \\
\text { (Euphorbiaceae) PCR } 59\end{array}$ & Velame & N & Emetic [P|2] & Root (maceration) & Oral \\
\hline Lantana camara L. (Verbenaceae) PCR 168 & Cãmará & $\mathrm{N}$ & Healing process [BA1] & Leaf (maceration) & Topic \\
\hline \multirow{2}{*}{$\begin{array}{l}\text { Lecythis pisonis Cambess (Lecythidaceae) } \\
\text { PCR } 120\end{array}$} & \multirow[t]{2}{*}{ Coco-de-sapucaia } & \multirow[t]{2}{*}{ N } & Flu [BA1] & Fruit (see recipe 8) & Oral \\
\hline & & & Bronchitis [BA1] & Fruit (see recipe 8) & Oral \\
\hline \multirow{2}{*}{$\begin{array}{l}\text { Myracrodruon urundeuva Allemão } \\
\text { (Anacardiaceae) PCR } 140\end{array}$} & \multirow[t]{2}{*}{ Aroeira } & \multirow[t]{2}{*}{ N } & Flu [PI1] & Bark (see recipe 12) & Oral \\
\hline & & & $\begin{array}{l}\text { Wash aggravated } \\
\text { eyes [BA2] }\end{array}$ & Branches (infusion) & Topic \\
\hline $\begin{array}{l}\text { Operculina macrocarpa (Linn) Urb. } \\
\text { (Convolvulaceae) PCR } 246\end{array}$ & $\begin{array}{l}\text { Batata-doce, batata-de- } \\
\text { purga }\end{array}$ & $\mathrm{N}$ & Blood purifying [PI2] & $\begin{array}{l}\text { Tuber (grid and soak } \\
\text { in water) }\end{array}$ & Oral \\
\hline Opuntia sp. (Cactaceae) [not collected] & Palma & UNK & $\begin{array}{l}\text { Labor (delivery of } \\
\text { placenta) [BA1] }\end{array}$ & Branches (see recipe 7) & Oral \\
\hline \multirow{2}{*}{$\begin{array}{l}\text { Polygala sp. (Polygalaceae) PCR 104, } \\
163,164\end{array}$} & \multirow[t]{2}{*}{ Cainaninha, puaia-branca } & \multirow[t]{2}{*}{ UNK } & Flu [BA1] & Aerial (see recipe 8) & Oral \\
\hline & & & $\begin{array}{l}\text { Asthmatic bronchitis } \\
\text { [BA1] }\end{array}$ & Aerial (see recipe 8) & Oral \\
\hline \multirow{2}{*}{$\begin{array}{l}\text { Ricinus communis L. (Euphorbiaceae) } \\
\text { PCR } 144\end{array}$} & \multirow[t]{2}{*}{ Mamona } & \multirow[t]{2}{*}{ E } & Laxative [BA5] & Seed (oil extraction) & Oral \\
\hline & & & Wound [BA5] & Seed (oil extraction) & Oral \\
\hline $\begin{array}{l}\text { Ruellia bahiensis (Nees) Morong. } \\
\text { (Acanthaceae) PCR 121, } 141\end{array}$ & Purga-do-campo & N & Fever [BA1] & All parts (infusion) & Oral \\
\hline $\begin{array}{l}\text { Sanseviera cylindrica Bojer (Liliaceae) } \\
\text { PCR } 242\end{array}$ & Espada-de-ogum-fechada & $\mathrm{E}$ & $\begin{array}{l}\text { To remove black } \\
\text { magic [BA2] }\end{array}$ & Leaf (see recipe 2) & Inhalation \\
\hline Sapotaceae (undefined species) PCR 109 & Buranhê & UNK & Chronic wound [BA1] & Bark (decoction) & Topic \\
\hline \multirow{2}{*}{$\begin{array}{l}\text { Schinopsis brasiliensis Engl. } \\
\text { (Anacardiaceae) PCR } 139\end{array}$} & \multirow[t]{2}{*}{ Braúna } & \multirow[t]{2}{*}{ N } & Diarrhea [BA2] & Branches (infusion) & Oral \\
\hline & & & To bless [BA2] & Branches (in natura) & Topic \\
\hline $\begin{array}{l}\text { Senna spectabilis (DC.) H.S. Irwin \&Barneby } \\
\text { (Fabaceae) PCR } 84\end{array}$ & São-joão & N & To bless [BA2] & Branches (in natura) & Topic \\
\hline Sida cordifolia L. (Malvaceae) PCR 202 & $\begin{array}{l}\text { Malva-do-campo, } \\
\text { malva-branca }\end{array}$ & N & Healing process [BA5] & Leaf(roast and grind) & Topic \\
\hline Sisyrinchium sp. (Iridaceae) PCR 134 & Capim-lanceta & UNK & Fever [BA2] & Leaf (infusion) & Oral \\
\hline $\begin{array}{l}\text { Solanum americanum Mill. (Solanaceae) } \\
\text { PCR 101, 199, } 250\end{array}$ & Erva-de-santa-maria & $\mathrm{N}$ & Pneumonia [PI1] & Aerial (maceration) & Oral \\
\hline Ximenia americana L. (Olacaceae) PCr 137 & Ameixa-braba & $\mathrm{N}$ & Healing process [PI2] & Bark (maceration) & Topic \\
\hline
\end{tabular}

"Native or naturalized (N), Exotic (E), Unknown origin (UNK)

common for treatment of "minor" problems, like gastritis, cough, and contusion, if compared to "serious" diseases like cancer, psychiatric disorders, and neurological conditions [3, 30, 31].

The therapeutic categories with higher ICF were gastrointestinal (0.42), genitourinary (0.41), psychoanaleptic (0.39), and respiratory (0.39), while the other categories presented ICF lower than 0.25 (Table 7). Low ICF values indicate that plants are chosen randomly or the informants do not exchange information about their use [28, 29]. As we can see, there was a low consensus among the participants, which in many cases cited different plants and uses for similar ailments. The most accepted interpretation is that the migrants do not share information about the species and uses, possibly because in many cases, the access to medicinal plants is no longer the primary health care adopted. Another hypothesis is that the adaptation to a new environment, with access to different medicinal plants, resulted in a heterogeneous use among the migrants, which reflects the low ICF value found for most therapeutic 
Table 4 Recipes and medicinal plants from the origin place which were no longer used by the informants (discontinuation) after their migration to Bororé Peninsula

\begin{tabular}{|c|c|c|c|c|c|}
\hline Scientific name (family)/voucher & Popular names & Origin $^{*}$ & Popular use/[interviewee] & $\begin{array}{l}\text { Plant part } \\
\text { (preparation method) }\end{array}$ & Route \\
\hline $\begin{array}{l}\text { Caesalpinia ferrea Mart. Ex Tul. var. } \\
\text { parvifolia (Fabaceae) PCR } 125\end{array}$ & Pau-ferro & $\mathrm{N}$ & $\begin{array}{l}\text { Homemade mercury for } \\
\text { medical use [BA5] }\end{array}$ & Bark (decoction) & Topic \\
\hline \multirow{2}{*}{$\begin{array}{l}\text { Chenopodium ambrosioides } L \text {. } \\
\text { (Chenopodiaceae) PCR 49, 61, 218, 253, } \\
255,328\end{array}$} & \multirow{2}{*}{$\begin{array}{l}\text { Erva-de-santa-maria, } \\
\text { mastruz, mentruz }\end{array}$} & \multirow[t]{2}{*}{$\mathrm{N}$} & Worm, vermifuge $[\mathrm{PI} 1]$ & Aerial (see recipe 13) & Oral \\
\hline & & & $\begin{array}{l}\text { To wash an increased mosquito } \\
\text { wound [PI1] }\end{array}$ & Aerial (maceration) & Topic \\
\hline Citrus sp. (Rutaceae) [not collected] & Laranja (Orange) & E & $\begin{array}{l}\text { "Sezão" (intermittent or cyclic } \\
\text { fever, such as caused by malaria) [PI1] }\end{array}$ & Leaf (infusion) & Oral \\
\hline $\begin{array}{l}\text { Diptychandra aurantiaca Tul } \\
\text { (Fabaceae) PCR } 204\end{array}$ & Birro-branco & $\mathrm{N}$ & Soap [PI2] & Bark (decoction) & Topic \\
\hline $\begin{array}{l}\text { Menispermaceae (undefined species) } \\
\text { PCR } 178\end{array}$ & Buticara, buti & UNK & Paludism, typhoid fever [BA1] & Fruit (decoction) & Oral \\
\hline $\begin{array}{l}\text { Operculina macrocarpa (Linn) Urb. } \\
\text { (Convolvulaceae) PCR } 246\end{array}$ & $\begin{array}{l}\text { Batata-doce, } \\
\text { batata-de-purga }\end{array}$ & N & Vermifuge [PI2] & $\begin{array}{l}\text { Tuber (grid and soak } \\
\text { in water) }\end{array}$ & Oral \\
\hline $\begin{array}{l}\text { Ricinus communis L. (Euphorbiaceae) } \\
\text { PCR } 144\end{array}$ & Mamona & E & Worm, vermifuge $[\mathrm{PI} 1]$ & Seed (see recipe 13) & Oral \\
\hline \multirow{2}{*}{$\begin{array}{l}\text { Ziziphus joazeiro Mart. (Rhamnaceae) } \\
\text { PCR } 88\end{array}$} & \multirow[t]{2}{*}{ Juá } & \multirow[t]{2}{*}{$\mathrm{N}$} & Dentifrice [PI2] & Bark (maceration) & Topic \\
\hline & & & Dandruff shampoo [PI2] & Bark (decoction) & Topic \\
\hline
\end{tabular}

${ }^{*}$ Native or naturalized (N), Exotic (E), Unknown origin (UNK)

categories. However, when we analyze the species and indication cited by migrants from the same state and biome, we can observe higher agreement of use (see Tables 2, 3, 4, and 5) suggesting that migrants that share a common background are more likely to exchange information. Low ICV values were also found in a previous study that evaluated the dynamics of use of medicinal plants among migrants living in Diadema [18].

Table 8 shows the 19 species cited at least five times by the interviewees. The species most cited were Foeniculum vulgare (10 recipes from 4 informants), Baccharis trimera (9 recipes from 3 informants), and Ruta graveolens (9 recipes from 2 informants)-see Tables 2, 3, 4, and 5. Table 8 also shows the index of relative importance of each plant, represented by the number of informants that cited the plant proportionally to the number of recipes. Lippia alba was the species used by the highest number of informants, with a relative importance of 0.86 , although cited to five different indications. A high relative importance (0.80) was also observed to Phyllanthus niruri and Phyllanthus tenellus (used to treat kidney stones by three migrants). On the other hand, we observed that Ruta chalepensis and Ruta graveolens are used by few informants for many different purposes. This suggests that these species may have particular importance for these informants, but not for the other migrants. It is interesting to note that all species in this list had the use maintained after migration, except for Calea pinnatifida, which use was incorporated by two informants after their migration to the Bororé Peninsula.

\section{Dynamics of use}

The category where each species was classified (maintenance, replacement, discontinuation, and incorporation) was defined according to the dynamics of use described by the interviewee after his/her migration to the Bororé Peninsula. One species could be used for different purposes (more than one recipe) and the dynamics of use could be different for each recipe and informant.

Table 9 shows the number of recipes and percentage of maintenance, replacement, incorporation, and discontinuation for each recipe considering each informant and the total sample. We observed that, on average, most uses were maintained (65.4\%) after the migration (206 recipes containing 80 species), 54 recipes (17.1\%) containing 39 species were replaced by plants available in the Bororé Peninsula, 45 new recipes (14.3\%) were incorporated, and only 3.2\% fell into disuse after migration, but these percentages are very different if we analyze the dynamic of use for each informant. It is clear that the knowledge about medicinal plants is very different among the participants. BA1 and BA2 cited most plants and recipes while BA3 showed a limited use of medicinal plants. It was previously reported that a large part of the knowledge about medicinal plants is not shared among migrants, and in many cases, the same species are used differently or for different ailments [13].

In general, we could observe highest rates of maintenance with migrants from Atlantic Forest (especially BA1, BA3, and BA4), while migrants from Caatinga biome (BA2, PI1, and PI2) presented lower percentages of maintenance (compared with the average of the total sample) 


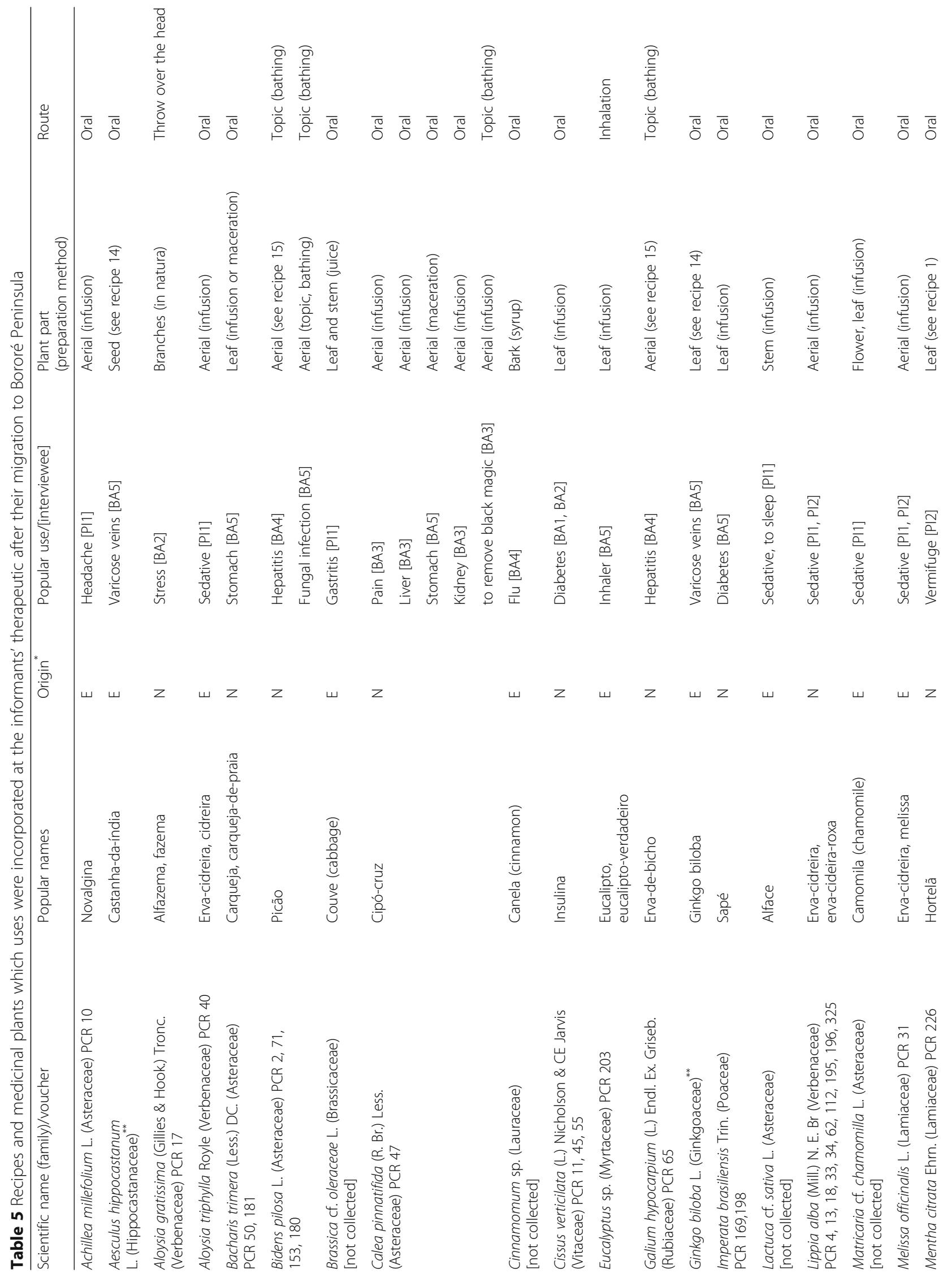




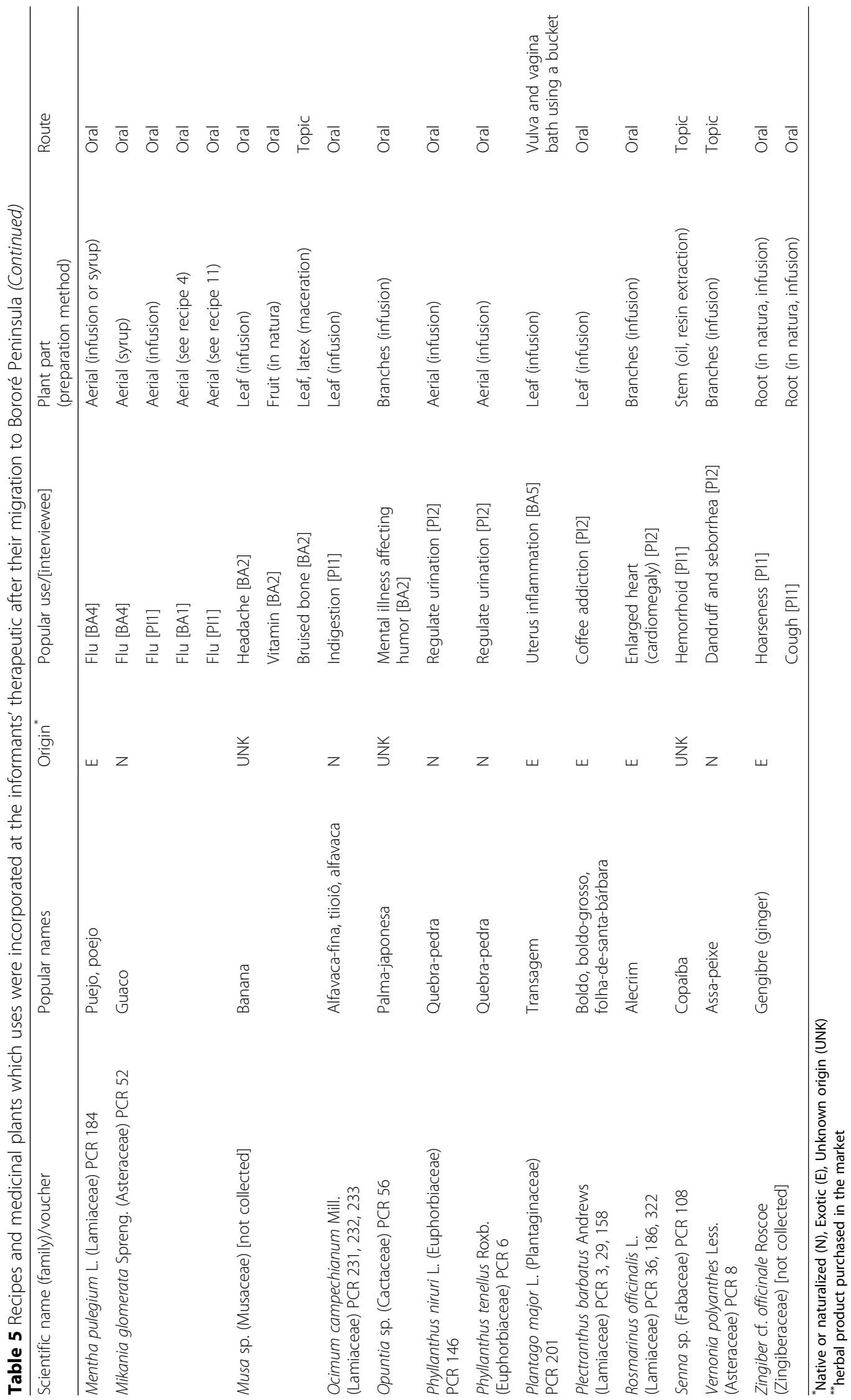


Table 6 Recipes containing two or more species and their methods of preparation

\begin{tabular}{|c|c|c|}
\hline Recipe number & Original recipe & Current recipe (after migration) \\
\hline 1 & Infusion with garlic (Allium sativum) & $\begin{array}{l}\text { Infusion of garlic bulb (A. sativum) and } \\
\text { mint leaves (Mentha citrata) }\end{array}$ \\
\hline 2 & $\begin{array}{l}\text { Incense prepared with leaves of Sanseviera cylindrica, leaves of } \\
\text { Aloysia gratíssima and Lippia alba }\end{array}$ & $\begin{array}{l}\text { Sanseviera cylindrica replaced by species } \\
\text { with similar use, when possible }\end{array}$ \\
\hline 3 & $\begin{array}{l}\text { Decoction of roasted seeds of Amburana cearenses and seeds } \\
\text { of Myristica fragans together with coffee (Coffea arabica) }\end{array}$ & $\begin{array}{l}\text { Recipe still used for gut pain, but the use } \\
\text { of } A \text {. cearenses for headache was replaced }\end{array}$ \\
\hline 4 & $\begin{array}{l}\text { Syrup prepared with cambuci (not collected), barks of pineaple } \\
\text { (Ananas comosus), leaves of Cymbopogon citratus, leaves or fruits } \\
\text { of Gossypium hirsutum, leaves of Eugenia uniflora, aerial parts of } \\
\text { Rosmarinus officinalis, branches of manjericão (Ocimum americanum } \\
\text { or Ocimum basilicum), leaves of Plectranthus amboinicus, and } \\
\text { flowers of Syzygium aromaticum }\end{array}$ & $\begin{array}{l}\text { Same recipe, but aerial part of Mikania } \\
\text { glomerata was incorporated }\end{array}$ \\
\hline 5 & $\begin{array}{l}\text { Leaves of lime and orange (Citrus sp.) macerated and mixed } \\
\text { with creolin }\end{array}$ & The same \\
\hline 6 & $\begin{array}{l}\text { Decoction prepared with seeds of Myristica fragans and aerial } \\
\text { parts of Foeniculum vulgare }\end{array}$ & The same \\
\hline 7 & $\begin{array}{l}\text { Infusion of aerial parts of Mentha arvensis, branches of Opuntia sp. } \\
\text { (Cactaceae), aerial parts of Mentha pulegium, and tuber of } \\
\text { cebola-branca (undefined species, Iridaceae) }\end{array}$ & Opuntia sp. is no longer used in the recipe \\
\hline 8 & $\begin{array}{l}\text { Syrup containing, fruits of Lecythis pisonis, aerial parts of Polygala sp. } \\
\text { (Polygalaceae), roots of quitara (undefined species, Arecaceae), } \\
\text { leaves of Kalanchoe pinnata and garapia (not collected) }\end{array}$ & $\begin{array}{l}\text { Lecythis pisonis, Polygala sp. and quitara } \\
\text { (Arecaceae) replaced by plants with } \\
\text { similar uses, like garlic (Allium sativum) }\end{array}$ \\
\hline 9 & Infusion of leaves of Vernonia condensata and aerial parts of Lippia alba & The same \\
\hline 10 & $\begin{array}{l}\text { Infusion of aerial parts of Mentha arvensis and seed oil of } \\
\text { Ricinus communis }\end{array}$ & The same \\
\hline 11 & Infusion of aerial parts of Mentha pulegium & $\begin{array}{l}\text { Syrup prepared with aerial parts of Mentha } \\
\text { pulegium and Mikania glomerata }\end{array}$ \\
\hline 12 & $\begin{array}{l}\text { Syrup prepared with barks of Anadenanthera macrocarpa, } \\
\text { barks of Myracrodruon urundeuva and jatobá } \\
\text { (Hymenaea courbaril or Hymenaea stigonocarpa) }\end{array}$ & Recipe replaced by the use of single species \\
\hline 13 & $\begin{array}{l}\text { Maceration prepared with saffron (not collected), aerial parts of } \\
\text { Chenopodium ambrosioides and mamona oil (Ricinus communis) }\end{array}$ & Recipe discontinued \\
\hline 14 & None & $\begin{array}{l}\text { Herbal remedy containing seeds of Aesculus } \\
\text { hippocastanum and leaves of Ginkgo biloba }\end{array}$ \\
\hline 15 & None & $\begin{array}{l}\text { Infusion of aerial parts of Bidens pilosa and aerial } \\
\text { parts of Galium hypocarpium }\end{array}$ \\
\hline
\end{tabular}

and showed higher rates of replacement, incorporation, and discontinuation (Table 9). This data suggest that native species from Caatinga biome were not available in the host place (Atlantic Forest biome) and could not be easily cultivated or acquired there. In fact, when we compared the species identified as native/naturalized or exotic, the percentage of maintained uses was found to be higher for exotic species, while the replacement and discontinuation was higher for native species (Fig. 3).

These dynamics of use and importance of therapeutic categories were previously discussed by several authors. Medeiros et at $[1,19]$ reported that migrants can adopt two main strategies when arriving the new environment: adaptation of the ethnomedical system to the new flora of the new place and acquisition of the original plants from the original place. The authors did not focus on internal migrations within a country, but many variables discussed are similarly valid in our study. Among the possible adaptations discussed, they cite the incorporation of new plant species or new uses for known species in the migrant pharmacopeia and the replacement of plants from the original flora by species with phylogenetic proximity or that possess similar morphological, chemical, and sensory characteristics. Leonti [32] also discusses the displacement of people and cross-cultural knowledge exchange using different concepts. The author reports that cultural interaction may alter the diversity and the importance of medicinal plants, which is detectable as continuity and disjunction or discontinuity and synchronism [32, 33].

It is important to point out that the study with migrant people has some limitations. In our study, we intended to compare the current use of medicinal plants by migrants 
Table 7 Popular uses, number of species used $\left(N_{t}\right)$, number of use citations (recipes) ( $N_{\text {ur }}$ ), and informant's consensus factor (ICF) calculated for each therapeutic category

\begin{tabular}{|c|c|c|c|c|}
\hline Therapeutic category & Popular uses & $N_{\mathrm{t}}$ & $N_{\mathrm{ur}}$ & ICF \\
\hline Birth control, childbirth & $\begin{array}{l}\text { Abortive and post-abortion care, labor (delivery of the placenta), } \\
\text { childbirth, for the baby to be born faster, recovery, and care after delivery }\end{array}$ & 8 & 9 & 0.13 \\
\hline Cardiovascular and hematological & $\begin{array}{l}\text { To the heart, hypertension, symptoms of heart attack, enlarged heart } \\
\text { (cardiomegaly), blood purifying, varicose veins, leukemia }\end{array}$ & 10 & 11 & 0.10 \\
\hline Contagious and tropical diseases & $\begin{array}{l}\text { Measles, chickenpox, smallpox, paludism, typhoid fever, "sezão" (intermittent } \\
\text { or cyclic fever, such as caused by malaria) }\end{array}$ & 5 & 6 & 0.20 \\
\hline Dermatological & $\begin{array}{l}\text { Allergy, itching, scabies, fungal infection, healing process, skin burn, wound, } \\
\text { chronic wound, to wash an increased mosquito wound, "bicheira" (pests, as } \\
\text { Tunga penetrans), homemade mercury for medical use, stop external } \\
\text { bleeding (injuries and scratches) }\end{array}$ & 21 & 23 & 0.09 \\
\hline Endocrine and metabolism & Diabetes, cholesterol & 4 & 5 & 0.25 \\
\hline Gastrointestinal & $\begin{array}{l}\text { To the stomach, liver, gut, indigestion, hangover, burning sensation on liver } \\
\text { and stomach, gastritis, hepatitis, emetic, gut motility, guts pain due to food, } \\
\text { worm, vermifuge, hemorrhoid, laxative, diarrhea, "ventosidade" (flatulence) }\end{array}$ & 34 & 58 & 0.42 \\
\hline Genitourinary & $\begin{array}{l}\text { Kidney, kidney stone, urethra and kidney problems, infection with vaginal } \\
\text { discharge, difficulty urinating, regulate urination, gynecological infection, } \\
\text { uterus inflammation, menorrhagia }\end{array}$ & 14 & 23 & 0.41 \\
\hline Hygiene & $\begin{array}{l}\text { Domestic hygiene, to vent the house, soap, dentifrice, dandruff shampoo, } \\
\text { armpit odor, seborrhea }\end{array}$ & 6 & 7 & 0.17 \\
\hline Inflammation, pain and fever & $\begin{array}{l}\text { Pain, fever, inflammation, body ache, headache, inflamed tooth, toothache, } \\
\text { pain due to dental caries (cavities), sore throat, inflammation from inside the } \\
\text { body, feeling sick, contusion, tendon inflammation, bruised bone, bowel pain, } \\
\text { abdominal pain, abdominal bloating, eye pain, eye injury (knock), eye } \\
\text { inflammation, wash aggravated eyes, sinusitis, otitis, rheumatism, hoarseness }\end{array}$ & 40 & 55 & 0.20 \\
\hline Magical & $\begin{array}{l}\text { Spiritual, to remove black magic, against evil eye, to bless, to prevent envy, } \\
\text { home protection, against stress (external use) }\end{array}$ & 21 & 26 & 0.20 \\
\hline Neonatal care & Baby belly button, baby teeth popping & 3 & 3 & 0.00 \\
\hline Psychoanaleptic & $\begin{array}{l}\text { Sedative, to sleep, to calm down, to children out of parental control, bad } \\
\text { feeling, mental illness affecting humor }\end{array}$ & 15 & 24 & 0.39 \\
\hline Respiratory problems & $\begin{array}{l}\text { Flu, cold, cough, whooping cough, breast congestion, expectorant, inhaler, } \\
\text { catarrh, bronchitis, asthmatic bronchitis, pneumonia, for the lungs }\end{array}$ & 38 & 62 & 0.39 \\
\hline Stimulant and fortifier & Anemia, stimulate appetite, vitamin, sexual weakness & 4 & 5 & 0.25 \\
\hline Others & Coffee addiction, weight loss & 2 & 2 & 0.00 \\
\hline
\end{tabular}

living in a metropolitan region and the therapeutic resource they had before migrating. However, we could not measure the "latent knowledge," which means that some species that were used in their hometowns possibly were not remembered, because they were not found in the host place or their use (indication) was no longer necessary. In this case, the number of replaced and discontinued species and recipes found in our study is possibly underestimated. Other factors can affect the chance of plants being forgotten, such as changes in the importance of certain use categories and differences in the prevalence of diseases [32]. In our study, most of the abandonments occurred for species used as vermifuges and to treat contagious or tropical diseases; the informants related that these problems could be treated with cheap and effective allopathic medicines (vermifuges) or the diseases are uncommon in the new environment (tropical diseases). Some authors warn that it is difficult to estimate how much knowledge about medicinal plants has been lost by migrants in comparison with people from their place of origin because, in most cases, no baseline data exist [1]. We carried out a bibliographic search in scientific databases and no ethnobotanical studies were found for the six cities of origin of our participants.

Another point for consideration is the importance of certain therapeutic resources which uses are maintained by migrants, despite their displacement to regions with different biome and culture and with better access to healthcare facilities. It was not our objective to search in databases if the popular use reported by the participants was already proven by scientific studies. However, we can observe that several plants cited were evaluated in pre-clinical studies or recognized by its traditional use, but only a few species were licensed as an herbal drug in the Brazilian market. As an example, we can cite Aesculus hippocastanum (antivaricose), Ananas comosus, Eucalyptus 
Table 8 Index of relative importance and dynamic of use of the most cited species

\begin{tabular}{|c|c|c|c|c|}
\hline Species & Number of citations & Number of informants & Dynamics $^{*}$ & Index ${ }^{* *}$ \\
\hline Aloysia gratissima & 5 & 2 & $M, I$ & 0.40 \\
\hline Anadenanthera macrocarpa & 6 & 3 & $M, R$ & 0.50 \\
\hline Bacharis trimera & 9 & 3 & $M, I$ & 0.33 \\
\hline Cajanus cajan & 8 & 4 & M & 0.50 \\
\hline Calea pinnatifida & 5 & 2 & । & 0.40 \\
\hline Chenopodium ambrosioides & 7 & 3 & $M, D$ & 0.43 \\
\hline Cymbopogon citratus & 8 & 4 & M & 0.50 \\
\hline Foeniculum vulgare & 10 & 4 & M & 0.40 \\
\hline Lippia alba & 7 & 6 & $M, I$ & 0.86 \\
\hline Mentha arvensis & 6 & 4 & M & 0.66 \\
\hline Mentha pulegium & 6 & 4 & $M, I$ & 0.66 \\
\hline Persea americana & 6 & 3 & M & 0.50 \\
\hline Phyllanthus niruri & 5 & 4 & $M, I$ & 0.80 \\
\hline Phyllanthus tenellus & 5 & 4 & $M, I$ & 0.80 \\
\hline Plectranthus amboinicus & 5 & 3 & M & 0.60 \\
\hline Rosmarinus officinalis & 5 & 3 & $M, I$ & 0.60 \\
\hline Ruta chalepensis & 5 & 1 & M & 0.20 \\
\hline Ruta graveolens & 9 & 2 & M & 0.22 \\
\hline Sambucus canadensis & 6 & 2 & M & 0.33 \\
\hline
\end{tabular}

${ }^{*} \mathrm{M}=$ maintained; $\mathrm{I}=$ incorporated; $\mathrm{D}=$ discontinued

${ }^{* *}$ Index of relative importance $=$ number of informants/number of citations

sp. and Mikania glomerata (expectorant), and Matricaria chamomilla (anxiolytic) which popular use is related to the therapeutic category approved [34]. In other cases, the species is licensed as an herbal product in a therapeutic category, but different popular uses are cited by the informants: Alpinia zerumbet (cited for cardiovascular use and registered as antispasmodic), Caesalpinia ferrea (employed as homemade mercury and approved as expectorant), Ginkgo biloba (used for varicose vein and approved as antivertiginous, antiplatelet agent and vasodilator), Lantana camara (cited as healing and registered as expectorant agent), Persea americana (several popular uses, but different of the registered use-anti-inflammatory), Schinus terebinthifolius (magical use and registered as anti-infective and healing agent), Syzygium aromaticum (used to treat flu and licensed as anti-dyspeptic drug), and Zingiber officinale (used to treat cough and hoarseness, but registered as antiemetic and antinauseant).

Table 9 Number of species and recipes cited by the informants and their dynamic of use

\begin{tabular}{|c|c|c|c|c|c|c|c|}
\hline \multirow[t]{2}{*}{ Migrant } & \multirow{2}{*}{$\begin{array}{l}\text { Number } \\
\text { of species }\end{array}$} & \multirow{2}{*}{$\begin{array}{l}\text { Number } \\
\text { of recipes }\end{array}$} & \multirow{2}{*}{$\begin{array}{l}\text { Recipes/ } \\
\text { species }\end{array}$} & \multicolumn{4}{|c|}{ Dynamic of use: number of recipes (percentage) } \\
\hline & & & & Maintained & Replaced & Discontinued & Incorporated \\
\hline $\mathrm{BA} 1^{*}$ & 70 & 110 & 1.57 & $91(82.7)$ & $16(14.5)$ & $1(0.9)$ & $2(1.8)$ \\
\hline $\mathrm{BA}^{* *}$ & 34 & 59 & 1.74 & $37(62.7)$ & $16(27.1)$ & $0(0.0)$ & $6(10.2)$ \\
\hline $\mathrm{BA}^{*}$ & 11 & 19 & 1.72 & $15(78.9)$ & $0(0.0)$ & $0(0.0)$ & $4(21.1)$ \\
\hline $\mathrm{BA}^{*}$ & 20 & 28 & 1.40 & $23(82.1)$ & $0(0.0)$ & $0(0.0)$ & $5(17.9)$ \\
\hline $\mathrm{BA}^{*}$ & 26 & 27 & 1.04 & $14(51.9)$ & $5(18.5)$ & $1(3.7)$ & $7(25.9)$ \\
\hline $\mathrm{Pl} 11^{* *}$ & 25 & 37 & 1.48 & $11(29.7)$ & $8(21.6)$ & $4(10.8)$ & $14(37.8)$ \\
\hline $\mathrm{Pl} 2^{* *}$ & 29 & 35 & 1.21 & $15(42.9)$ & $9(25.7)$ & $4(11.4)$ & $7(20.0)$ \\
\hline Total & 131 & 315 & 2.40 & $206(65.4)$ & $54(17.1)$ & $10(3.2)$ & 45 (14.3) \\
\hline
\end{tabular}

*migrants from Atlantic Forest biome

** migrants from Caatinga biome 


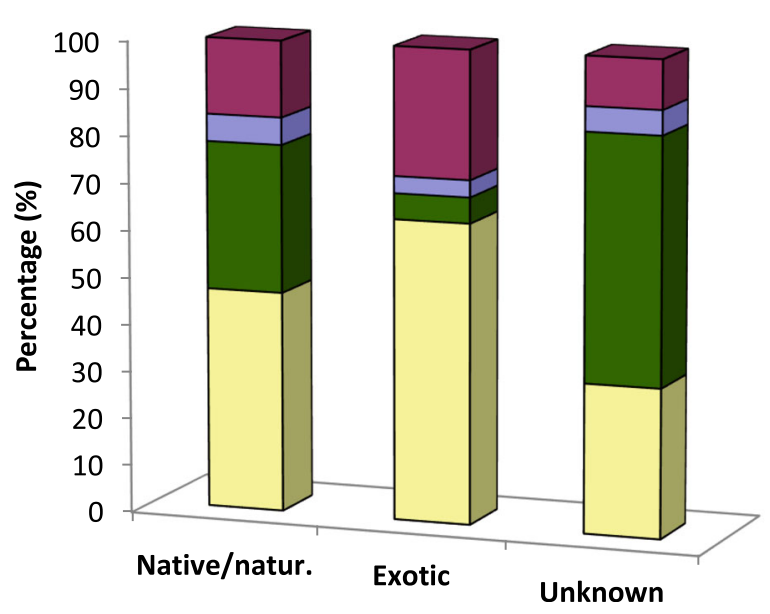

$\square$ Incorporated

$\square$ Discontinued

$\square$ Replaced

$\square$ Maintained

Fig. 3 Percentage of species native/naturalized, exotic, or from unknown origin which were maintained, replaced, discontinued, or incorporated

\section{Qualitative analysis - the dynamics of medicinal plants use}

As previously discussed by other authors, many factors can affect the use of medicinal plants by migrants: differences in the flora of the new environment, the access to cultivated or fresh medicinal plants, the local culture and knowledge about medicinal plants, prevalence of diseases and access to health system, media influence, among others $[1,10,13,15,18,35]$. The reasons that drive the dynamics of medicinal plant use by different migrants may also depend on personal choices. The qualitative analysis of the interviews allows understanding the individual reasons that justify the maintenance, replacement, abandonment, or incorporation of certain medicinal plant uses.

The migrants interviewed stated that upon their arrival in São Paulo, they looked for plants previously known in their hometowns. Most medicinal uses of species already known in their original regions were maintained at Bororé Peninsula, mainly for exotic plants or species with wide geographical distribution, as previously discussed. In many cases, native species from the Atlantic Forest (predominant biome of Esplanada, Jitaúna, and Itabuna) were also found at Bororé. On the other hand, the maintenance of species endemic to the Caatinga was difficult due to the considerable climatic difference, which made it challenging to find these species or to cultivate them in the new biome at São Paulo metropolitan region.

In some cases, we observed the cultivation of plants they considered of greater importance. For instance, BA1 received from his nephew (coming from Bahia) seeds and seedlings of Amburana cearensis and Commiphora leptophloeos, both species known as emburana and employed to alleviate the symptoms of indigestion. The migrants also used to find the same species of their original regions in local emporiums, herbal houses, or street fairs, as described by other authors [36-38]. However, the interviewees prefer to avoid getting plants from these sources whenever possible, because the botanical material is generally kept in bad conditions and subjected to contamination and deterioration, as also described in other studies [39, 40].

When the migrants did not find the species from their original region, they tried to replace them with similar plants from the new region guided by different strategies: conversation with neighbors; information from popular books and local media; and observing the ingestion of plants by animals or looking for species with organoleptic characteristics similar to those of the original species, in order to reach similar effects, as also observed with other populations [18, 41-43]. In some cases, several plants were mentioned as possible options (substitutes) for the replaced plants and recipes.

In our study, we observed that many species of the same genus, although recognized as different plants by the participants, were employed for the same indications: Ocimum americanum, O. basiicum, O. campechianum, and $O$. gratissimum (employed to treat flu) or Phyllanthus amarus, P. niruri, and P. tenellus (used as anti-inflammatory and against kidney stone). We also observed that even species from different genus and family, but sharing similar morphology or characteristics like odor and taste, are used for similar purposes, as is the case of Aloysia triphylla and Lippia alba (Verbenaceae) both known as erva-cidreira and used as a sedative/to sleep or Plectranthus barbatus (Lamiaceae) and Vernonia condensata (Asteraceae) 
known as boldo/boldo-do-chile and employed for hangover and indigestion. This makes sense considering that plants with close organoleptic properties have higher chance to have similar chemical constitution and that morphological and organoleptic properties are the basis for the doctrine of signature $[32,41,44]$.

As previously mentioned, many species not found were from Caatinga biome and were replaced by local ones. Examples of species replaced are pimentinha (Croton betulaster), employed as anxiolytic/sedative in Novo Horizonte and replaced by pitanga (Eugenia uniflora) or são-joão (Senna spectabilis) and braúna (Schinopsis brasiliensis), employed as magical (to bless) by relatives of BA2 and replaced by alfazema (Aloysia gratissima). At the same time that some native species were replaced, in particular those endemic, other naturalized or exotic plants were incorporated. This fact can be explained by the increasing cultivation and adaptation of several exotic medicinal plants in different geographic regions, as observed to sálvia (Salvia officinalis) and camomila (Matricaria chamomilla) and by the use of teas and sachets infusions from Asian and European species, which are easily found in supermarkets, as reported by other studies carried out in different Brazilian regions [45-47].

In addition, our study suggests that the introduction of species from Bororés Atlantic Forest on the migrants' therapeutic resources is slower than the introduction of exotic species often cultivated in the city of São Paulo. Moreover, some species that are currently found in the entire country were incorporated into the interviewees' therapeutic practice only after they moved to Bororé Peninsula, as is the case of guaco (Mikania glomerata).

Occasionally, the migrants' therapeutics would include different species for the same purpose and they could maintain the use when one or more species were found in Bororé. Interviewee BA1 used both the capim-de-aruanda (Cymbopogon densiflorus) and guiné (Petiveria alliacea) to prevent black magic, but since he could not find the first species in Bororé Peninsula, he limited himself to the second one. On the other hand, we observed that the knowledge about the occurrence and medicinal properties of some plants from Borore was not always shared among the residents. Interviewees BA3 and BA4 alleged to maintain the use of buticara (Menispermaceae-undetermined species) for toothache, collecting the plant on Bororés Forest, while BA1 did not find this species. Similarly, interviewee BA2 maintained the use of angico (Anadenanthera macrocarpa) as anxiolytic ("when you have a bad feeling") and for wound treatment, while PI1 and PI2 did not find the species and discontinued its use against flu, cold, and for cardiovascular problems (blood purifying). BA1 reported to find aroeira (Myracrodruon urundeuva) at Bororés Forest and maintained its use to bless (magical), while PI1 did not find the species on the local Forest and changed the recipe (formula) used to prepare an expectorant syrup to treat flu and cold. The same strategies of replacement and incorporation were cited by Garcia et al. [18] for a similar group of migrants.

Vegetables and fruits often found in the migrants' diet with attributed medicinal properties were also named. Some vegetables were already used in their hometown in either or both contexts (as food and medicine), such as lettuce (Lactuca sativa) and pomegranate (Punica granatum), employed by PI1 as a sedative and to treat sore throat, respectively. Other examples are pineapple (Ananas comosus), pitanga (Eugenia uniflora), and basil (Ocimum basilicum), employed against flu by BA1. The diet of the interviewees was altered in order to consume more vegetables classified as prophylactic or useful for the treatment of diseases acquired or detected in the new environment, as also reported in other studies $[4,5,14,48,49]$. An increase in knowledge about food medicines was also observed in migrants from the Dominican Republic living in New York [20], in agreement with our data pointing that the acquisition of vegetables (including medicinal food) in big cities may be facilitated.

When we consider the category of use, we observe that several incorporations are related to pathologies that the informants claimed do not exist or be very uncommon in their hometowns. Plants reported to act as sedatives such as chamomile (Matricaria chamomilla) and erva-cidreira (Aloysia triphylla and Lippia alba) began to be used against stress because the city life imposes a greater risk to mental health, according to interviewees. However, it is likely that some diseases could not be diagnosed in their hometowns, because some diagnostics would require sophisticated laboratory tests and, at the time they moved, their hometowns did not have an adequate public health system. As an example, we can cite the cardiac hypertrophy detected in PI2 by clinical exams performed after relocation to a metropolitan area and treated with rosemary (Rosmarinus officinalis).

Several discontinuations occurred due to the availability of alternative therapies or allopathic medicines with low cost, as the use of mentruz (Chenopodium ambrosioides), castor oil extracted from castor beans (Ricinus communis), and batata-de-purga (Operculina macrocarpa) against worms, which were less palatable than allopathic medicines according to the interviewees, and because these medications are sold over the counter. In addition, access to basic sanitation also contributed to the decreased incidence of infectious diseases.

Other plants were no longer used for some purposes (discontinuation/abandonment), and industrialized products were used in their place. As an example, we can cite pauferro (Caesalpinia ferrea), used by BA5 on the preparation 
of home mercury, or plants used to make products of personal hygiene, as juá (Ziziphus joazeiro), which bark was used by PI1 to get a dentifrice and an anti-dandruff shampoo, or birro-branco (Diptychandra aurantiaca), used by PI2 to prepare home soap in his hometown. The use of industrialized products instead of natural products may be explained possibly because the access to drugstores and industrialized products is easier in the urban metropolis, and also, due to the best economic situation and purchasing power of the migrants in relation to the time when they lived in their hometowns. According to Haselmair et al. [50], the continuation of the traditional medicinal health practices is challenged by increasing industrialization and globalization where the use of medicinal plants is starting to play a secondary role.

Even though the interviewees had better access to drugstores, they kept the use of several medicinal plants and named some species with brand names of allopathic drugs, which suggests that the use of medicinal plants by the informants is not falling away, but being constantly modified. We can cite as an example the Novalgina (Achillea millefolium), employed as analgesic by PI1, and the insulin (Cissus verticillata) used by BA1 and BA2 to reduce the hyperglycemia. In fact, the use of active principles or brand name of drugs to name medicinal plants was previously related in other studies $[18,51]$.

Taken together, these reports are in agreement with previous literature showing that the use of medicinal plants in an urban context is not static and is constantly changing and adapting to the current life conditions $[1,2$, $19,32]$. It is important to highlight that the seven informants, despite characterized as experts and users of medicinal plants, began to use the public health service system, since they considered the official therapeutics an additional treatment option. Access to the public system also influenced the discontinuation of plants to treat some infectious diseases, since they had access to vaccination programs. However, the interviewees declared that they kept the use of medicinal plants whenever their experiences indicated that it would be more efficacious than pharmaceutical drugs. Other studies [10, 36, 52, 53] also observed the simultaneous use of traditional and official therapeutic as a consequence of living in an urban region with easy access to drugstores and public health. In a study with Asian migrants living in the UK, up to $82 \%$ of participants who took prescription medicines did not tell their healthcare professionals about any herbal medicine they consumed [9]. Health professionals should be aware of this concomitant treatment option, since it can alter the efficacy and safety of many drugs $[38,54,55]$.

\section{Conclusion}

We observed cross-cultural adaptations on the migrants' ethnomedicine after migration to a metropolitan region.
Factors like the biome and occurrence of the species, prevalence of some diseases, and the local knowledge were listed as reasons to change the use of medicinal plants. The migration extended their knowledge regarding the diversity of therapies available in a big metropolis. Despite recognizing the benefits of the conventional health care, the interviewees opted for maintaining the use of certain medicinal plants, in addition to the replacement and incorporation of novel species, with slower incorporation of species from the native local forest. On the other hand, the maintenance of traditional uses by the population over time demonstrates the high cultural value of the ethnomedical application of these species, suggesting that their potential as pharmacological agents should be evaluated.

\section{Additional file}

Additional file 1: Brazilian books consulted in order to obtain data on their geographical distribution and used to classify the species in native, naturalized or exotic. List of supplementary bibliography consulted. (DOCX $14 \mathrm{~kb}$ )

\section{Abbreviations}

BA: Migrants from the state of Bahia; ICF: Informant's Consensus Factor; PI: Migrants from the state of Piauí; RI: Index of relative importance

\section{Acknowledgments}

We are grateful for the valuable contribution to this study provided by the guides and interviewees and to Dr. Milene Lara Brownlow for reviewing the translation to English. We thank Dr. Eliana Rodrigues for her contribution on the study design, José Carlos Galduróz, MD, for helping on the therapeutic classification of uses/diseases, Dr. Lucia Rossi for botanical identification and Drs Andréa Onofre de Araújo and Ana Paula Moraes for accepting the voucher specimens on the UFABC herbarium.

\section{Funding}

The authors thank Associação Fundo de Incentivo à Psicofarmacologia (AFIP) and the Conselho Nacional de Desenvolvimento Científico e Tecnológico (CNPq) for the main author's graduate fellowship and to Centro Brasileiro de Informações sobre Drogas Psicotrópicas (CEBRID) for the financial support for the field work. There was no funding body associated with the writing of the manuscript or the decision to submit the manuscript for publication.

\section{Availability of data and materials}

The voucher specimens were deposited in UFABC Herbarium, under the collection numbers from 1 to 334 (PCR-Romanus, PC). Data generated during this study are included in this published article and additional information may be provided on reasonable request.

\section{Authors' contributions}

PCR collected and analyzed the data and wrote the manuscript. FRM and EAC critically reviewed the data and contributed to the manuscript. All authors have seen and approved the submitted final manuscript.

\section{Ethics approval and consent to participate}

The project was approved by the ethics committee of UNIFESP (Protocol \#0268/05), followed the recommendations for fieldwork and participation in the survey was voluntary, not obligatory. Participants were informed about the study objectives and consent was obtained prior to this study being carried out. 


\section{Competing interests}

The authors declare that they have no competing interests.

\section{Publisher's Note}

Springer Nature remains neutral with regard to jurisdictional claims in published maps and institutional affiliations.

\section{Author details}

${ }^{1}$ Department of Psychobiology, UNIFESP, Rua Botucatu, 862, $1^{\circ}$ andar, prédio Ciências Biomédicas, Vila Clementino, São Paulo, SP 04023-062, Brazil. Center for Natural and Human Sciences, UFABC, Rua Arcturus, 03, Sala 236, Bloco Delta. Bairro Jardim Antares, São Bernardo do Campo, SP 09606-070, Brazil. ${ }^{3}$ Department of Preventive Medicine, UNIFESP, Rua Botucatu, 740, $4^{\circ}$ andar. Bairro Vila Clementino, São Paulo, SP 04023-900, Brazil.

Received: 25 March 2018 Accepted: 2 November 2018

Published online: 22 November 2018

\section{References}

1. Medeiros PM, Soldati GT, Alencar NL, Vandebroek I, Pieroni A, Hanazaki N, Albuquerque UP. The use of medicinal plants by migrant people: adaptation, maintenance, and replacement. Evid Based Complement Alternat Med. 2012. https://doi.org/10.1155/2012/807452.

2. Pieroni A, Vandebroek I, editors. Traveling cultures and plants: the ethnobiology and ethnopharmacy of human migrations. New York: Berghahn Books; 2007.

3. Ceuterick M, Vandebroek I, Torry B, Pieroni A. Cross-cultural adaptation in urban ethnobotany: the Colombian folk pharmacopoeia in London. J Ethnopharmacol. 2008;120(3):342-59.

4. Jiang S, Quave CL. A comparison of traditional food and health strategies among Taiwanese and Chinese immigrants in Atlanta, Georgia, USA. J Ethnobiol Ethnomed. 2013. https://doi.org/10.1186/1746-4269-9-61.

5. Pieroni A, Nebel S, Quave C, Münz H, Heinrich M. Ethnopharmacology of liakra: traditional weedy vegetables of the Arbëreshe of the vulture area in southern Italy. J Ethnopharmacol. 2002;81(2):165-85.

6. Ellena R, Quave CL, Pieroni A. Comparative medical ethnobotany of the Senegalese community living in Turin (northwestern Italy) and in Adeane (southern Senegal). Evid Based Complement Alternat Med. 2012;2012: 604363. https://doi.org/10.1155/2012/604363.

7. Cano JH, Volpato G. Herbal mixtures in the traditional medicine of Eastern Cuba. J Ethnopharmacol. 2004;90(2-3):293-316.

8. Volpato G, Godínez D, Beyra A, Barreto A. Uses of medicinal plants by Haitian immigrants and their descendants in the province of Camagüey, Cuba. J Ethnobiol Ethnomed. 2009:5:16. https://doi.org/10.1186/1746-4269-5-16.

9. Bhamra SK, Slater A, Howard C, Johnson M, Heinrich M. The use of traditional herbal medicines amongst South Asian diasporic communities in the UK. Phytother Res. 2017;31(11):1786-94.

10. Ceuterick M, Vandebroek I, Pieroni A. Resilience of Andean urban ethnobotanies: a comparison of medicinal plant use among Bolivian and Peruvian migrants in the United Kingdom and in their countries of origin. J Ethnopharmacol. 2011;136:27-54.

11. Ceuterick M, Vandebroek I. Identity in a medicine cabinet: discursive positions of Andean migrants towards their use of herbal remedies in the United Kingdom. Soc Sci Med. 2017;177:43-51.

12. Pieroni A, Cianfaglione K, Nedelcheva A, Hajdari A, Mustafa B, Quave CL. Resilience at the border: traditional botanical knowledge among Macedonians and Albanians living in Gollobordo, Eastern Albania. J Ethnobiol Ethnomed. 2014. https://doi.org/10.1186/1746-4269-10-31.

13. Kujawska M, Hilgert NI. Phytotherapy of Polish migrants in Misiones, Argentina: legacy and acquired plant species. J Ethnopharmacol. 2014:153:810-30.

14. Kujawska M, Pieroni A. Plants used as food and medicine by polish migrants in Misiones, Argentina. Ecol Food Nutr. 2015;54(3):255-79.

15. Pirker H, Haselmair R, Kuhn E, Schunko C, Vogl CR. Transformation of traditional knowledge of medicinal plants: the case of Tyroleans (Austria) who migrated to Australia, Brazil and Peru. J Ethnobiol Ethnomed. 2012. https://doi.org/10.1186/1746-4269-8-44.

16. Miara MD, Bendif H, Ait Hammou M, Teixidor-Toneu I. Ethnobotanical survey of medicinal plants used by nomadic peoples in the Algerian steppe. J Ethnopharmacol. 2018:219:248-56.

17. Santos FSDS, Muaze MAF. Tradições em movimento: uma etnohistória da saúde e da doença nos vales dos rios Acre e Purus. 1st ed. Brasília: Paralelo $15 ; 2002$.
18. Garcia D, Domingues MV, Rodrigues E. Ethnopharmacological survey among migrants living in the Southeast Atlantic Forest of Diadema, São Paulo, Brazil. J Ethnobiol Ethnomed. 2010. https://doi.org/10.1186/1746-4269-6-29.

19. Medeiros PM, Abreu DBO, Albuquerque UP. Plant knowledge and use in the context of migration. In: Albuquerque UP, Alves R, editors. Introduction to ethnobiology. Switzerland: Springer International Publishing; 2016. https:// doi.org/10.1007/978-3-319-28155-1_39.

20. Vandebroek I, Balick MJ. Globalization and loss of plant knowledge: challenging the paradigm. PLoS One. 2012;7(5):e37643. https://doi.org/10. 1371/journal.pone.0037643.

21. van Andel T, Westers $P$. Why Surinamese migrants in the Netherlands continue to use medicinal herbs from their home country. J Ethnopharmacol. 2010;127:694-701.

22. Capobianco JPR, Whately M. Billings 2000. Ameaças e perspectivas para o maior reservatório de áqua da região metropolitana de São Paulo. Relatório do Diagnóstico Socioambiental Participativo da Bacia Hidrográfica da Billings no período 1989-1999. 2002. http://www.socioambiental.org/ banco_imagens/pdfs/56.pdf. Accessed 09 Mar 2011.

23. Etkin NL. Anthropological methods in ethnopharmacology. J Ethnopharmacol. 1993;38(2-3):93-104.

24. Alexiades MN. Selected guidelines for ethnobotanical research: a field manual. New York: the New York botanical garden; 1996.

25. Flora do Brasil 2020 em construção. Jardim Botânico do Rio de Janeiro. Available in: http://floradobrasil.jbrj.gov.br/. Accessed in: 10 Ago. 2018.

26. Romanus PC. Manutenção, substituição, abandono e incorporação dos usos de plantas medicinais entre os migrantes moradores da península do Bororé, na Represa Billings, SP. MSc dissertation. São Paulo: Universidade Federal de São Paulo; 2008. p. 145

27. International Classification of Diseases 11 st ed. Available in: http://www. who.int/classifications/icd/en/. Accessed 3 July 2018.

28. Heinrich M, Ankli A, Frei B, Weimann C, Sticher O. Medicinal plants in Mexico: healers' consensus and cultural importance. Soc Sci Med. 1998; 47(11):1859-71.

29. Gazzaneo LRS, de Lucena RFP, Albuquerque UP. Knowledge and use of medicinal plants by local specialists in a region of Atlantic Forest in the state of Pernambuco (Northeastern Brazil). J Ethnobiol Ethnomed. 2005. https://doi.org/10.1186/1746-4269-1-9.

30. Monteiro JM, Ramos MA, Araújo Ede L, Amorim EL, Albuquerque UP. Dynamics of medicinal plants knowledge and commerce in an urban ecosystem (Pernambuco, Northeast Brazil). Environ Monit Assess. 2011; 178(1-4):179-202.

31. Medeiros PM, Albuquerque UP, Abreu DBO, Silva TC, Ferreira Junior WS, Ramos MA, Ladio AH. What drives the use of natural products for medicinal purposes in the context of cultural pluralism? Eur J Integr Med. 2016;8:471-7.

32. Leonti M. The future is written: impact of scripts on the cognition, selection, knowledge and transmission of medicinal plant use and its implications for ethnobotany and ethnopharmacology. J Ethnopharmacol. 2011;134:542-55.

33. Bye R, Linares E, Estrada E. Biological diversity of medicinal plants in México. In: Arnason JT, Mata R, Romeo JT, editors. Phytochemistry of medicinal plants. Recent advances in Phytochemistry (proceedings of the Phytochemical Society of North America), vol. 29. Boston: Springer; 1995. p. 65-82. https://doi.org/10.1007/978-1-4899-1778-2_4.

34. Carvalho ACB, Lana TN, Perfeito JPS, Silveira D. The Brazilian market of herbal medicinal products and the impacts of the new legislation on traditional medicines. J Ethnopharmacol. 2018;212:29-35.

35. Kujawska M, Pardo-de-Santayana M. Management of medicinally useful plants by European migrants in South America. J Ethnopharmacol. 2015;172: 347-55.

36. Balick MJ, Kronenberg F, Ososki AL, Reiff M, Fugh-Berman A, O'Connor B, Roble M, Lohr P, Atha D. Medicinal plants used by Latino healers for women's health conditions in New York City. Econ Bot. 2000;54(3):344-57.

37. Balick MJ, Muenz H, Akbulut M, Baser KHC, Durmuskahya C. Traditional phytoterapy and trans-cultural pharmacy among Turkish migrants living in Cologne, Germany. J Ethnopharmacol. 2005;102(1):69-88.

38. Kokkini S, Hanlidou E, Karousou R, Kleftoyanni V. The herbal market of Thessaloniki (New Greece) and its relation to the ethnobotanical tradition. J Ethnopharmacol. 2004;91 (2-3):281-99.

39. Sahoo N, Manchikanti P, Dey S. Herbal drugs: standards and regulation. Fitoterapia. 2010;81:462-71.

40. Soares Neto JAR, Kato EM, Bugno A, Galduróz JCF, Marques LC, Macrini T, Rodrigues E. Informal trade of psychoactive herbal products in the city of 
Diadema, SP, Brazil: quality and potential risks. Evid Based Complement Alternat Med. 2013. https://doi.org/10.1155/2013/894834.

41. Leonti M, Sticher O, Heinrich M. Medicinal plants of the Popoluca, Mexico: organoleptic properties as indigenous selection criteria. J Ethnopharmacol. 2002;81(3):307-15

42. Almeida MZ. Plantas Medicinais. 1st ed. Salvador: EDUFBA; 2003.

43. Pieroni A, Torry B. Does the taste matter? Taste and medicinal perceptions associated with five selected herbal drugs among three ethnic groups in West Yorkshire, Northern England. J Ethnobiol Ethnomed. 2007. https://doi. org/10.1186/1746-4269-3-21,

44. Medeiros PM, Santos Pinto BL, do Nascimento VT. Can organoleptic properties explain the differential use of medicinal plants? Evidence from Northeastern Brazil. J Ethnopharmacol. 2015;159:43-8.

45. Albuquerque UP. Re-examining hypotheses concerning the use and knowledge of medicinal plants: a study in the Caatinga vegetation of NE Brazil. J Ethnobiol Ethnomed. 2006;2:1-10.

46. Hanazaki N, Tamashiro JY, Leitão-Filho HF, Begossi A. Diversity of plant uses in two Caiçara communities from the Atlantic Forest coast, Brazil. Biodivers Conserv. 2000;9:597-615.

47. Pinto EPP, Amorozo MCM, Furlan A. Conhecimento popular sobre plantas medicinais em comunidades rurais da mata atlântica - Itacaré, BA, Brasil. Acta Bot Bras. 2006;20(4):751-62.

48. Tapsell LC, Hemphill I, Cobiac L, Patch CS, Sullivan DR, Fenech M, Roodenrys S, Keogh JB, Clifton PM, Williams PG, Fazio VA, Inge KE. Health benefits of herbs and spices: the past, the present, the future. Med J Aust. 2006;185(4): $4-24$.

49. Lentini F, Venza F. Wild food plants of popular use in Sicily. J Ethnobiol Ethnomed. 2007:3:1-12.

50. Haselmair R, Pirker H, Kuhn E, Vogl CR. Personal networks: a tool for gaining insight into the transmission of knowledge about food and medicinal plants among Tyrolean (Austrian) migrants in Australia, Brazil and Peru. J Ethnobiol Ethnomed. 2014;10:1. https://doi.org/10.1186/1746-4269-10-1.

51. Pires JM, Mendes FR, Negri G, Duarte-Almeida JM, Carlini EA. Antinociceptive peripheral effect of Achillea millefolium L. and Artemisia vulgaris L.: both plants known popularly by brand names of analgesic drugs. Phytother Res. 2009;23:212-9.

52. Reiff M, O'Connor B, Kronenberg F, Balick MJ, Lohr P, Roble M, Fugh-Berman A, Johnson KD. Ethnomedicine in the urban environment: Dominican healers in New York city. Hum Organ. 2003;62(1):12-26.

53. Wayland $C$. The failure of pharmaceuticals ad the power of plants: medicinal discourse as a critique of modernity in the Amazon. Soc Sci Med. 2004;58: 2409-19.

54. Calitz C, Steenekamp JH, Steyn JD, Gouws C, Viljoen JM, Hamman JH. Impact of traditional African medicine on drug metabolism and transport. Expert Opin Drug Metab Toxicol. 2014;10(7):991-1003.

55. Gallo E, Pugi A, Lucenteforte E, Maggini V, Gori L, Mugelli A, Firenzuoli F, Vannacci A. Pharmacovigilance of herb-drug interactions among preoperative patients. Altern Ther Health Med. 2014;20(2):13-7.

Ready to submit your research? Choose BMC and benefit from:

- fast, convenient online submission

- thorough peer review by experienced researchers in your field

- rapid publication on acceptance

- support for research data, including large and complex data types

- gold Open Access which fosters wider collaboration and increased citations

- maximum visibility for your research: over $100 \mathrm{M}$ website views per year

At BMC, research is always in progress.

Learn more biomedcentral.com/submissions 